\title{
Warm Rain Rates from AMSR-E 89-GHz Brightness Temperatures Trained Using CloudSat Rain-Rate Observations ${ }^{\mathscr{D}}$
}

\author{
RYAN EASTMAN \\ Department of Atmospheric Sciences, University of Washington, Seattle, Washington \\ MATTHEW LEBSOCK \\ Jet Propulsion Laboratory, California Institute of Technology, Pasadena, California \\ ROBERT WOOD \\ Department of Atmospheric Sciences, University of Washington, Seattle, Washington
}

(Manuscript received 16 October 2018, in final form 14 March 2019)

\begin{abstract}
Collocated CloudSat rain rates and Advanced Microwave Scanning Radiometer for EOS (AMSR-E) 89-GHz brightness temperature $T_{b}$ retrievals allow for the development of an algorithm to estimate light, warm rain statistics as a function of AMSR-E 89-GHz $T_{b}$ for shallow marine clouds. Four statistics are calculated from CloudSat rainfall rate estimates within each $4 \mathrm{~km} \times 6 \mathrm{~km} T_{b}$ pixel sampled by both sensors: the probability of rainfall, the mean rain rate, the mean rate when raining, and the maximum rain rate. Observations with overlying cold clouds are removed from the analysis. To account for confounding variables that modify $T_{b}$, curves are fit to the mean relationships between $T_{b}$ and these four statistics within bins of constant column-integrated water vapor from AMSR-E, and sea surface temperature and wind speed from reanalysis grids. The coefficients that define these curves are then applied to all available AMSR-E $T_{b}$ retrievals to estimate rain rate throughout the eastern subtropical oceans. A preliminary analysis shows strong agreement between AMSR-E rain rates and the CloudSat training dataset. Comparison with an existing microwave precipitation product shows that the new statistical product has an improved sensitivity to light rain. A climatology for the year 2007 shows that precipitation rates tend to be heavier where the sea surface is warmer and that rain is most frequent where stratocumulus transitions to trade cumulus in the subtropics.
\end{abstract}

\section{Introduction}

Subtropical marine stratocumulus clouds (Sc) act to cool Earth's climate because of their broad spatial extent, high albedo, warm cloud-top temperatures, and location near the equator (Randall et al. 1984; Slingo 1990; Hartmann et al. 1992). A significant amount of study has been invested in determining which environmental controls have the greatest effect on the temporal evolution of these clouds (Mauger and Norris 2010; Sandu and Stevens 2011; Eastman and Wood 2016; Burleyson and Yuter 2015a,b). Past studies suggest

\footnotetext{
Supplemental information related to this paper is available at the Journals Online website: https://doi.org/10.1175/JTECH-D-180185.s1.
}

Corresponding author: Ryan Eastman, rmeast@atmos.washington.edu that precipitation often coincides with a change in cellular structure, with heavy drizzle seen on the boundary between closed cells and neighboring open cells (Stevens et al. 1998, 2005; Comstock et al. 2005; Wood et al. 2008, 2011a). In this context, closed stratocumulus cells resemble a honeycomb with broad individual cloud elements separated by relatively small clear regions, while open cells are characterized by fields of shallow convective cores surrounded by thin, detraining clouds with relatively broad cloudless spaces between cells. Burleyson and Yuter (2015b), however, demonstrated that mesoscale stratocumulus cloud fraction has little sensitivity to drizzle at lag times of $1-3 \mathrm{~h}$. Whether drizzle is a cause of this breakup or a symptom of other processes acting to break up the clouds is an ongoing puzzle, currently limited by precipitation data availability and a lack of sensitivity to light rain over the remote oceans. While the CloudSat precipitation products 
provide the best available estimates of precipitation frequency and intensity in shallow marine clouds, the nadir-only sampling of CloudSat is insufficient for work attempting to disentangle cause and effect in drizzle and cloud processes. Recently, new satellite data products utilizing passive microwave observations of brightness temperature $T_{b}$ (Miller and Yuter 2013, hereafter MY13; Duncan et al. 2018) have shown the potential for vastly improved remote sensing of drizzle in shallow marine boundary layer clouds.

The use of high-frequency passive microwave $T_{b}$ has shown significant potential for estimating liquid water path (LWP), particularly around $90 \mathrm{GHz}$, where the $T_{b}$ response to LWP is 6 times greater than at $30 \mathrm{GHz}$. (Crewel and Löhnert 2003; Bobak and Ruf 2000; Petty 1994). This makes the Advanced Microwave Scanning Radiometer for EOS (AMSR-E; Wentz and Meissner 2004) passive microwave $89-\mathrm{GHz}$ brightness temperatures (Ashcroft and Wentz 2006) well suited to detecting LWP in warm boundary layer clouds. Higher LWP in these low clouds is shown to be associated with more observed precipitation (Comstock et al. 2004; Geoffroy et al. 2008; Abel et al. 2010; Lebsock et al. 2008), allowing precipitation occurrence to be inferred from $89-\mathrm{GHz}$ brightness temperature.

As described in Petty (1994) and MY13, $T_{b}$ observed by a satellite sensor for a certain frequency and wavelength is the sum of upward emissions from hydrometeors, the ocean surface, and humidity throughout the column minus any absorption by gases and scattering by ice particles. View angle may also affect observed $T_{b}$ since photons viewed at wider angles have a longer pathlength to the sensor, and because emission of microwaves can be anisotropic. Therefore, a $T_{b}$ retrieval provides an inaccurate measure of rain rate without information about surface emissivity, controlled by both temperature and roughness due to wind waves, and the abundance of water vapor and ice in the column. Currently available datasets using other microwave and infrared channels as well as reanalyses are now capable of quantifying confounding variables such as sea surface temperature, wind speed, column water vapor, and cloud-top temperature. Controlling for these variables allows for much more accurate quantifications of precipitation occurrence and intensity derived from $T_{b}$.

Based on limited ship-based radar observations in the southeast Pacific, MY13 have built a binary precipitation product that detects the presence of heavier drizzle in marine Sc. They posit that the largest variance in LWP will be seen on spatial scales equivalent to the sizes of individual drizzle cells. Their routine estimates liquid water path using the AMSR-E $T_{b}$ at $89 \mathrm{GHz}$ while also accounting for the varying background $T_{b}$ caused by varying column-integrated water vapor. If the retrieved $T_{b}$ within a $4 \mathrm{~km} \times 6 \mathrm{~km}$ pixel exceeds a $T_{b}$ threshold equivalent to a LWP of $200 \mathrm{~g} \mathrm{~m}^{-2}$, then heavy drizzle is reported. This binary product marks an improvement in sensitivity and resolution over existing passive-microwave-derived precipitation products.

Comparisons between collocated AMSR-E 89-GHz $T_{b}$ and C-band radar retrievals from the VAMOS OceanCloud-Atmosphere-Land Study Regional Experiment (VOCALS-REx) campaign (Wood et al. 2011b) in MY13 (their Fig. 1) show that the spatial patterns in $T_{b}$-derived precipitation coincide very well with the patterns of precipitation shown by the radar. The spaceborne radar carried aboard CloudSat creates a powerful opportunity to expand on this approach to a much larger dataset spanning diverse geography and meteorology. Because CloudSat and the Aqua satellite carrying the AMSR-E instrument are orbiting only one minute apart in formation, millions of CloudSat rain-rate retrievals (Lebsock and L'Ecuyer 2011) and AMSR-E 89-GHz $T_{b}$ retrievals are collocated in both space and time. This overlap of retrievals allows for a direct comparison of radar-retrieved rain rates and $89-\mathrm{GHz} T_{b}$. The collocated observations can then be used to create a robust analysis comparing rain rate to $T_{b}$ for a variety of atmospheric conditions.

Here we will expand on the work done by MY13 by using the collocated CloudSat and AMSR-E retrievals to establish mean relationships between $T_{b}$ and rain rate in subtropical $\mathrm{Sc}$ and trade cumulus $(\mathrm{Cu})$ clouds. To this end we will use CloudSat as a training dataset while controlling for a number of confounding factors, such as column-integrated water vapor, surface wind speed, sea surface temperature, and overlying ice clouds, detected by the Moderate Resolution Imaging Spectroradiometer (MODIS) aboard Aqua. Using the mean relationships between $T_{b}$ and rain rate we will present a routine that estimates for each $T_{b}$ value: the probability that precipitation is occurring, the mean rain rate associated with that $T_{b}$, the mean rain rate when raining, and the maximum likely rain rate. Using this routine, we develop a climatology of $T_{b}$-derived light rain rates that are comparable to existing CloudSat-derived climatologies in the subtropics developed by Leon et al. (2008) and Rapp et al. (2013). Eventually, a twice-daily, swath-level rain-rate product will be produced for light rain rates in the subtropics.

\section{Data}

\section{a. Stratocumulus and trade cumulus study regions}

Data for this work are currently restricted to the year 2007 and are sampled only within the four subtropical 


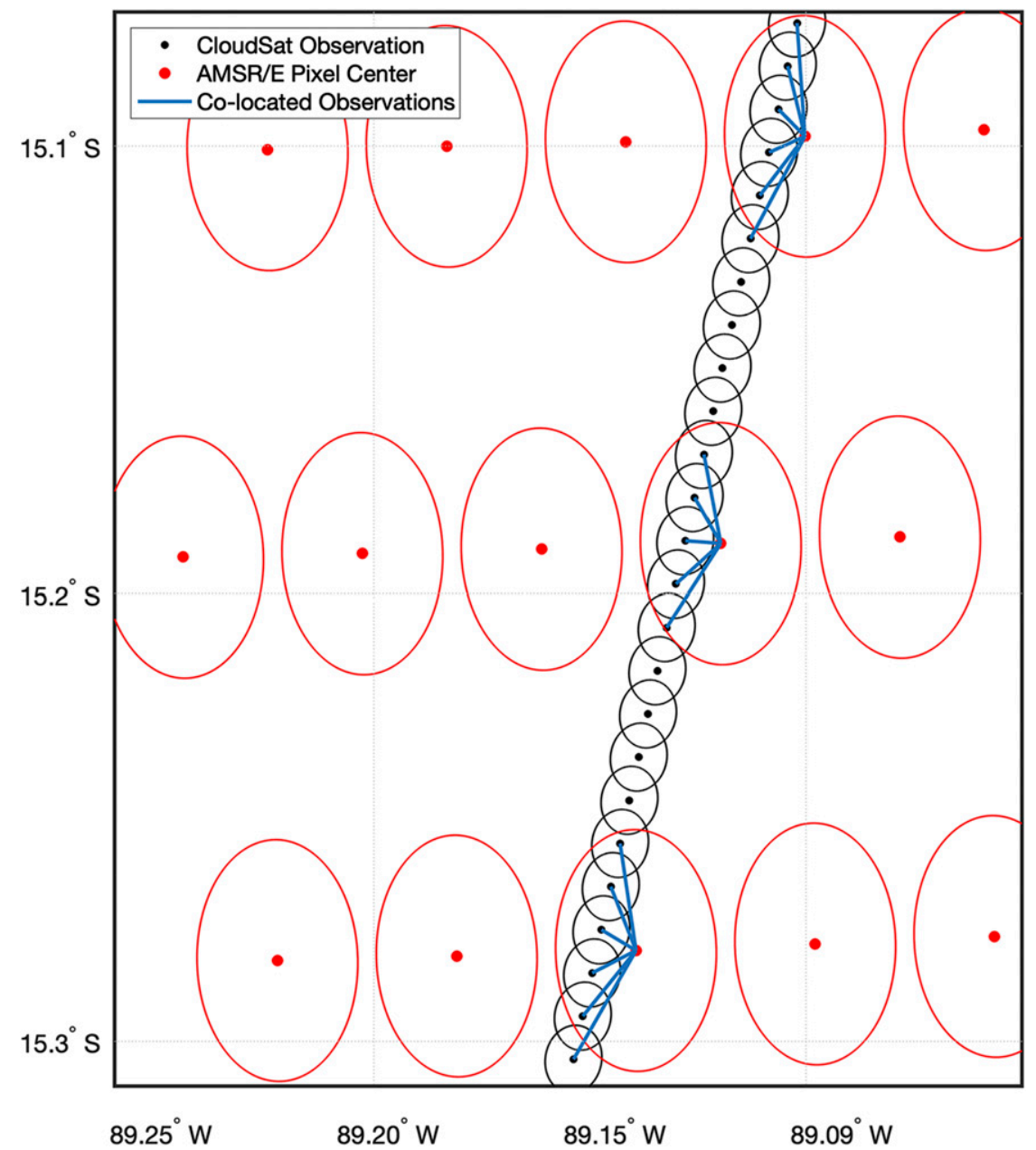

FIG. 1. Individual, coinciding CloudSat soundings and AMSR-E $T_{b}$ pixels during a descending node in the southeast Pacific. Observations connected by a blue line are assumed to be spatially and temporally (within $1 \mathrm{~min}$ ) collocated. Ellipses represent the estimated size and shape of each instruments field of view. (CloudSat, black: $1.4 \mathrm{~km}$ across track, $1.7 \mathrm{~km}$ along track; AMSR-E, red: $4 \mathrm{~km}$ across track, $6 \mathrm{~km}$ along track).

stratocumulus regions used in Eastman and Wood (2016): The northeast Pacific $\left(15^{\circ}-30^{\circ} \mathrm{N}, 155^{\circ}-115^{\circ} \mathrm{W}\right)$, southeast Pacific $\left(30^{\circ}-5^{\circ} \mathrm{S}, 105^{\circ}-70^{\circ} \mathrm{W}\right)$, southeast Atlantic $\left(30^{\circ}-5^{\circ} \mathrm{S}, 15^{\circ} \mathrm{W}-15^{\circ} \mathrm{E}\right)$, and eastern Indian $\left(30^{\circ}-20^{\circ} \mathrm{S}\right.$, $\left.60^{\circ}-110^{\circ} \mathrm{E}\right)$ Oceans. These regions were chosen in order to study the geographic maxima in Sc amount as well as the regions farther offshore where Sc transitions to trade $\mathrm{Cu}$ clouds. They contain few overlying ice clouds and are often free of organized synoptic-scale weather systems that may cause multilayered clouds or heavy, mixedphase precipitation.

\section{b. 89-GHz AMSR-E microwave brightness temperatures}

Microwave brightness temperatures are measured by the AMSR-E (Wentz and Meissner 2004; Ashcroft and
Wentz 2006) sensor for the year 2007. The AMSR-E sensor operated aboard the Aqua satellite as part of the A-Train satellite constellation. The A-Train crosses the equator at 0130 and 1330 local times, making those the approximate sample times in the subtropics. The AMSR-E has a swath width of $1445 \mathrm{~km}$, and the $89-\mathrm{GHz}$ $T_{b}$ is sampled in an arcing pattern with pixel sizes of approximately $4 \mathrm{~km} \times 6 \mathrm{~km}$. Although pixel resolution is $4 \mathrm{~km} \times 6 \mathrm{~km}$, pixel centers are separated by $10 \mathrm{~km}$ in the along-track direction, leaving a $\sim 4$-km gap between pixels.

The 89-GHz $T_{b}$ measures both horizontal and vertical polarization. As established in MY13, we use the horizontal polarization in the statistical algorithm because it has a larger dynamic range and is slightly less noisy than the vertical polarization (MY13; Jones and Vonder Haar 1997). 


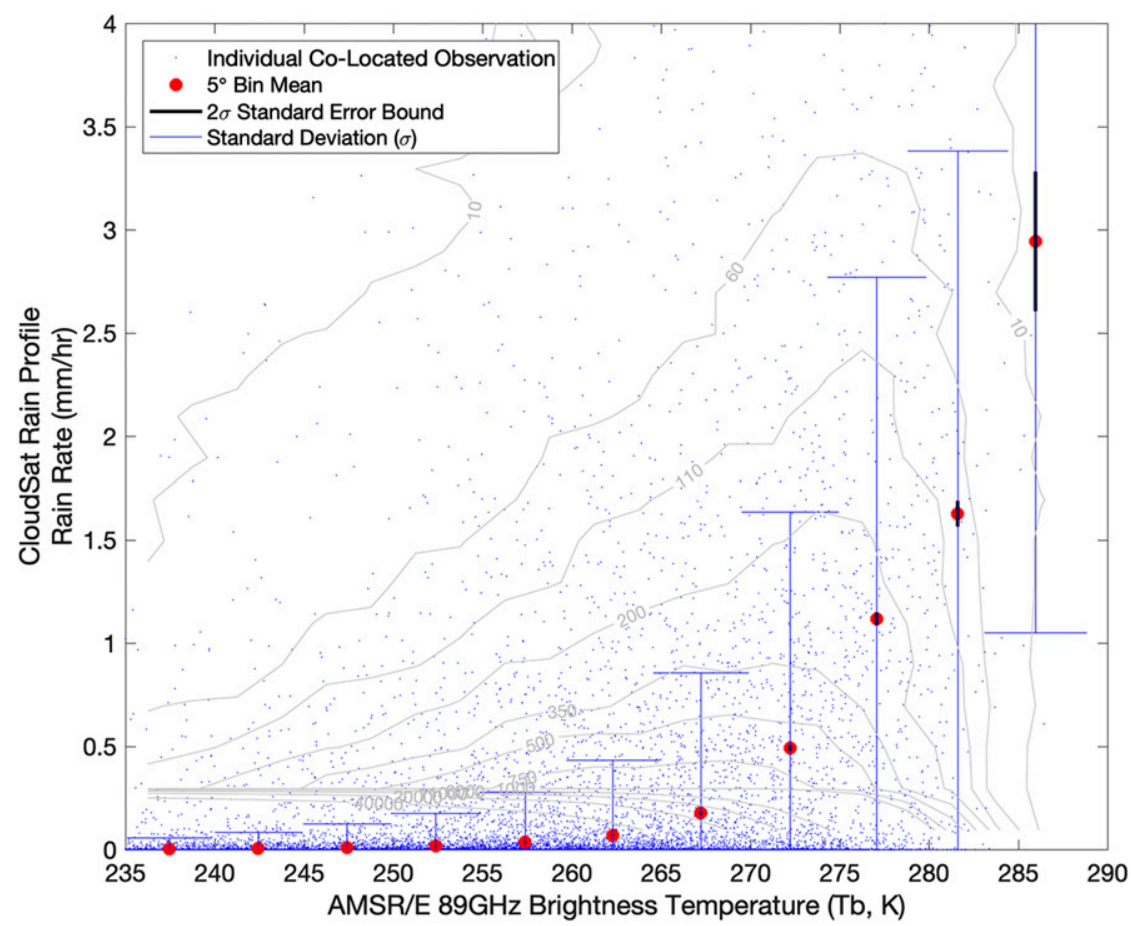

FIG. 2. CloudSat surface rain rates from the rain-profile product as a function of the collocated $89-\mathrm{GHz} T_{b}$. Individual coinciding observations are shown as blue dots ( 1 in 20 are shown). The 5-K bin means are shown as red dots; $2 \sigma$ standard error bounds for each 5-K bin mean are shown by the black vertical bars. Gray lines are a scatter density plot of all individual collocated observations, using a grid spacing of $2.5 \mathrm{~K}$ along $x$ and $0.2 \mathrm{~mm} \mathrm{~h}^{-1}$ along $y$. Standard deviations for each bin mean rain rate are shown as the blue error bars.

\section{c. Rain rate from CloudSat rain profile}

Rain-rate retrievals come from the $94-\mathrm{GHz}$ nadirlooking, cloud-profiling radar aboard CloudSat (Stephens et al. 2002), which was a part of the A-Train satellite constellation for the time period studied here. CloudSat continuously samples a "curtain" within the swath of AMSR-E, allowing for radar observations to be concurrent in space and time with the $89-\mathrm{GHz} T_{b}$ retrievals. The CloudSat along-track interval per radar burst is around $1.7 \mathrm{~km}$ with a swath width of $1.4 \mathrm{~km}$. The footprint of a CloudSat precipitation sample is much smaller compared to the AMSR-E $T_{b}$ grid, which allows for several CloudSat observations to coincide with a single $T_{b}$ pixel. We address this further below in section 3 .

To measure rainfall, we use the CloudSat 2-C rainprofile $\mathrm{R} 04$ product. This product provides an estimate of warm rainfall rate at the surface and is stated to be sensitive to rain rates as low as $0.001 \mathrm{~mm} \mathrm{~h}^{-1}$ (L'Ecuyer and Stephens 2002; Lebsock and L'Ecuyer 2011). Complete attenuation of the radar beam is rare in the subtropics, which is why we initially constrain our project to just the subtropical Sc regions. In the rare event of complete attenuation before sensing the surface, rain rates are flagged with a minus sign, then assigned the largest measured rate before full attenuation. These measurements are included in this analysis (by using the absolute value of all CloudSat rain rates) since there was no detectable sensitivity to their inclusion or exclusion.

\section{d. Water vapor, sea surface temperature, 10-m wind speed, rain rate, and ice clouds}

To better constrain the relationship between rain rate and $T_{b}$, we use several meteorological variables that are known to affect the observed $T_{b}$ : column-integrated water vapor (CWV), sea surface temperature (SST), 10-m wind speed (WSP), and ice clouds. Column-integrated water vapor is sourced from the AMSR-E Aqua environmental suite of L3 data (version 7; Wentz et al. 2014) on a regular $0.25^{\circ} \times 0.25^{\circ}$ latitude-longitude grid. Sea surface temperature is taken from the surface skin temperature contained in the ERA-Interim reanalysis on a $1^{\circ} \times 1^{\circ}$ latitude-longitude grid (Dee et al. 2011). Wind speed is sourced from the ERA-Interim 10-m wind speed. Ice clouds are detected by MODIS L2 collection 6 cloudtop temperatures resampled on a $5 \mathrm{~km} \times 5 \mathrm{~km}$ grid (MYDATML2; Platnick et al. 2017a,b; available online at 


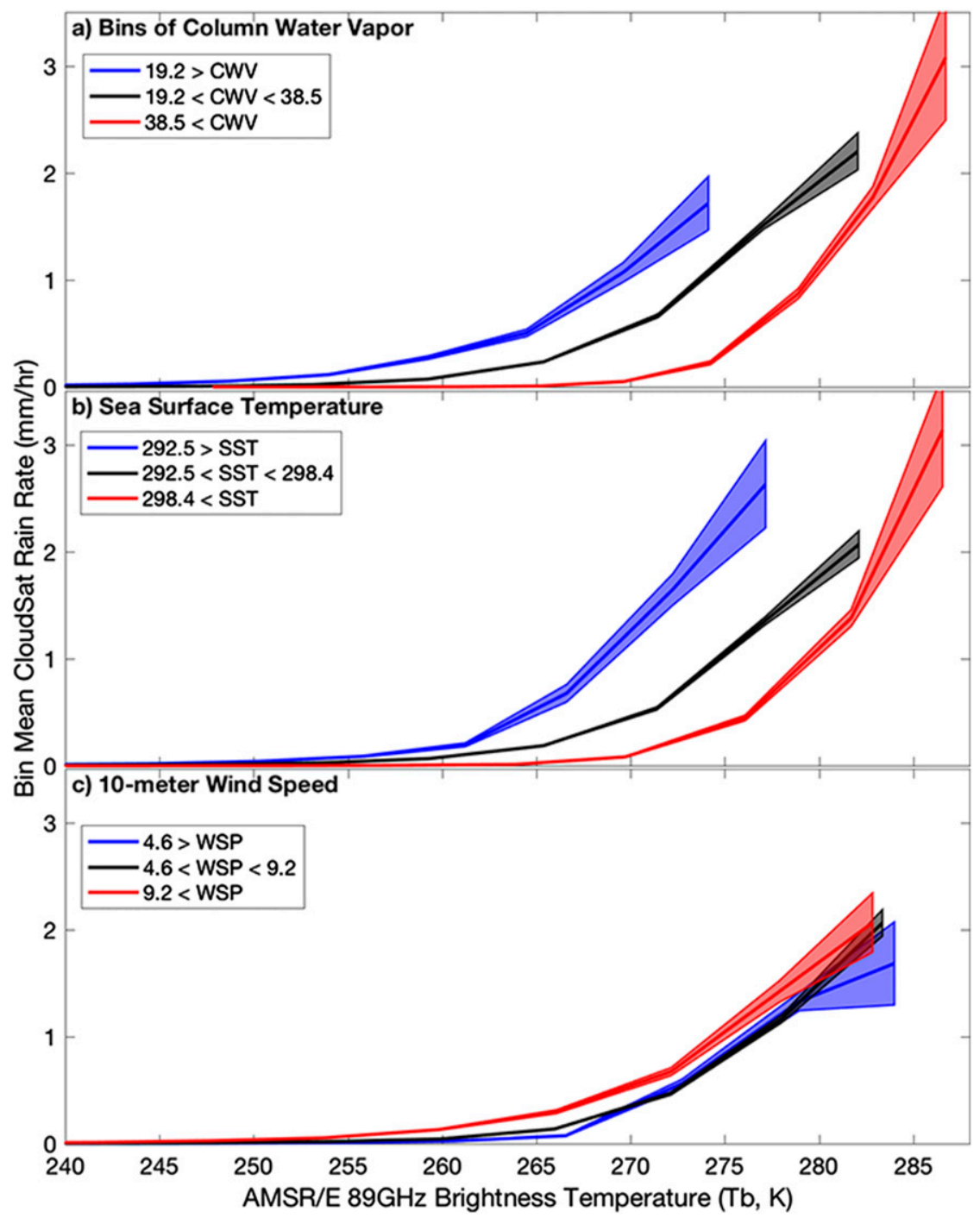

FIG. 3. Mean CloudSat rain-profile rain rates as a function of $T_{b}$ for bins of (a) CWV, (b) SST, and (c) WSP. Standard error bounds $(2 \sigma)$ are shown as shaded regions to highlight that these subsets of matched points are distinct from one another, and their differences must be accounted for.

https://ladsweb.modaps.eosdis.nasa.gov/missions-andmeasurements/products/12-joint-atmosphere/MYDATML2/). If an AMSR-E $T_{b}$ pixel falls within a MODIS L2 pixel containing a cloud top cooler than $263 \mathrm{~K}$ (10 K below freezing), then that AMSR-E pixel is likely to contain ice along with supercooled water and is excluded from our analysis.

\section{e. Comparison with existing swath-level rain-rate data}

To compare the rain-rate estimates created here with an existing satellite-based, passive microwave product, we use the instantaneous surface rain rates and probabilities of precipitation provided in the AMSR-E Aqua level-2B precipitation product (AE_Rain; Kummerow et al. 2015). The AE_Rain product is available at the swath level for pixel sizes roughly $5 \mathrm{~km}$ across track and $10 \mathrm{~km}$ along track. Though AE_rain has a similar spatial resolution compared the $89-\mathrm{GHz} T_{b}$, it is slightly coarser and spatially resampled, so pixels are not perfectly geographically collocated with the $89-\mathrm{GHz} T_{b}$ pixels. Rain rates contained in AE_rain are derived from brightness temperatures from lower-frequency channels, not just $89 \mathrm{GHz}$, so $\mathrm{AE}$ _rain rates tend to be less sensitive to drizzle, but more suitable for measuring convective precipitation.

\section{Methods}

As mentioned above, multiple CloudSat observations tend to coincide with a single AMSR-E pixel. This is 

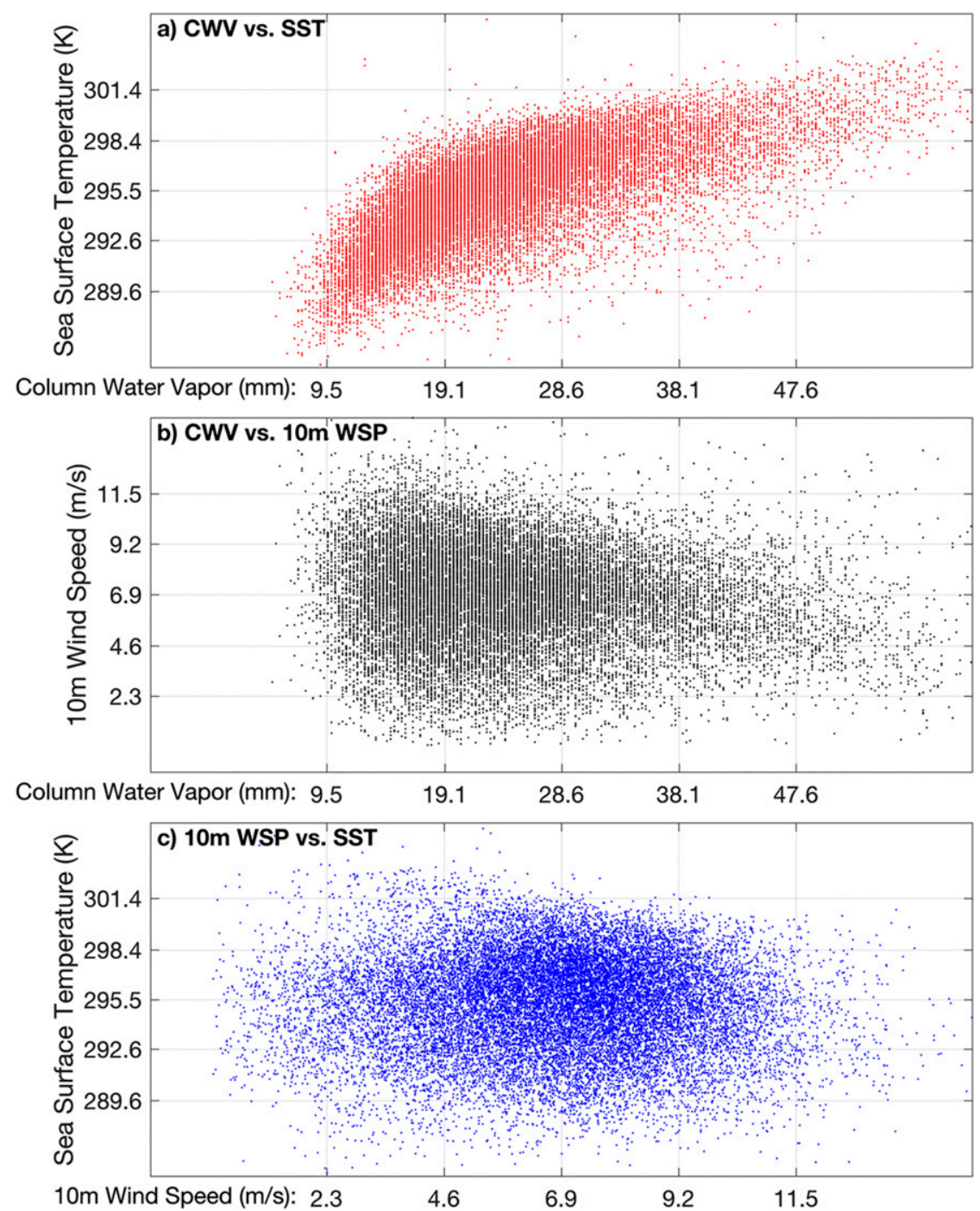

FIG. 4. Two-dimensional projections of a three-dimensional plot of environmental variables known to effect $T_{b}$ for each $T_{b}$ observation in our study; $1 \sigma$ bin boundaries are shown by the axis labels and grid lines. (a) Column water vapor plotted against sea surface temperature, (b) column water vapor plotted against 10-m wind speed, and (c) 10-m wind speed plotted against sea surface temperature.

shown more clearly in Fig. 1 where individual CloudSat soundings are plotted on a map along with AMSR-E pixels. Collocated observations in Fig. 1 are connected by lines. For each AMSR-E pixel there are $\sim 5-6$ coinciding CloudSat observations within the pixel.

An initial relationship between collocated $89-\mathrm{GHz}$ $T_{b}$ and CloudSat rain rate is seen in Fig. 2 where each CloudSat AMSR-E collocated observation is treated independently, meaning $T_{b}$ pixels are shown multiple times, so that all CloudSat observations are shown individually. Figure 2 shows the relationship between CloudSat rain rate and $T_{b}$ for all subtropical observations during 2007. Every twentieth collocated observation is plotted as a blue dot and $5-\mathrm{K}$ bin mean rain rates are shown by red dots with $2 \sigma$ standard error bounds (meaning twice as wide as the standard error bounds as calculated with one standard deviation) shown as the vertical black bars. A scatter density plot showing the number of collocated observations per unit area on the figure is also shown as the gray contour. Standard deviation is shown as a blue error bar. On average, rain rates are higher when $T_{b}$ is higher. This is due to the increase in the number of hydrometeors emitting microwaves in the $89-\mathrm{GHz}$ band. There is significant scatter in the data, however. Some of this spread is caused by the nonunique mapping of precipitation rate into $T_{b}$ 


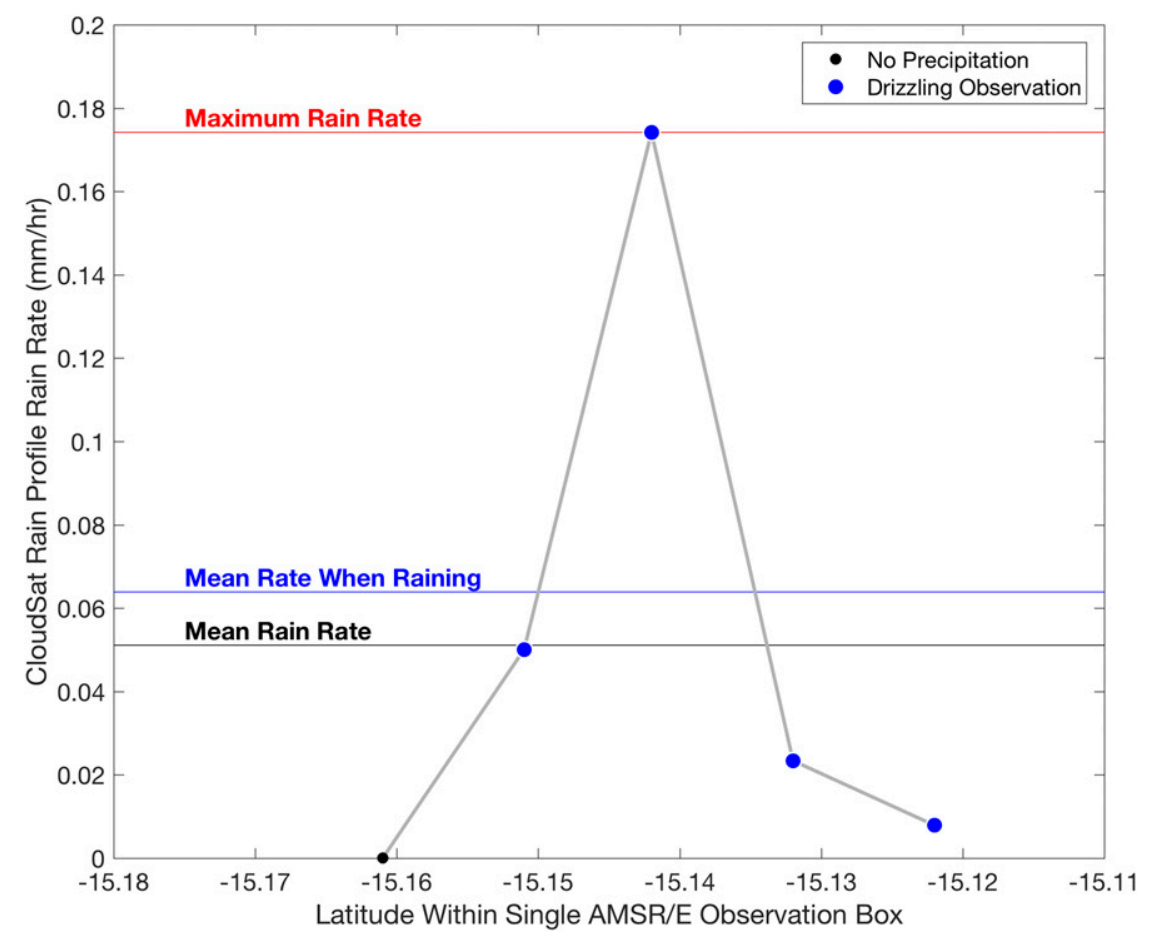

FIG. 5. Rain rates from CloudSat rain profile within a single $4 \mathrm{~km} \times 6 \mathrm{~km}$ AMSR-E $T_{b}$ pixel. The mean rain rate is the mean of all CloudSat rain rates including rate $=0$, the mean rate when raining is the mean of only those CloudSat rates detecting precipitation, and the maximum rain rate is the greatest CloudSat rain rate observed within the AMSR-E pixel. Collocated values discussed hereafter refer to these three quantities within each AMSR-E pixel.

pixels, since CloudSat footprints fail to sample the entire $T_{b}$ pixel, but other significant sources of noise are the confounding variables that are addressed below.

One considerable source of noise in Fig. 2 comes from the differences in background $T_{b}$ seen by AMSR-E due to environmental differences. The SST, CWV, and wind speed are all varying in Fig. 2 and differences in those variables drive differences in $T_{b}$ observed by AMSR-E independent of precipitation. To highlight this, in Fig. 3 we have separated our collocated observations into bins based on CWV, SST, and wind speed and fit curves to the mean relationships seen between rain rate and $T_{b}$ for each bin. Standard error $(2 \sigma)$ bounds are shown by the shaded regions for each bin. Bin bounds used to group our confounding variables are $2 \sigma$ standard deviations added or subtracted from the mean value of each variable. Figure 3 a shows that the $T_{b} /$ rain-rate relationship is significantly modified by the column water vapor. When $\mathrm{CWV}$ is high, precipitation coincides with considerably warmer $T_{b}$ compared to when CWV is low. A similar relationship is seen in Fig. $3 \mathrm{~b}$ where an equivalent rain rate coincides with warmer $T_{b}$ when SST is high compared to low. Finally, Fig. $3 \mathrm{c}$ shows that wind speed has a less powerful, but still noticeable, effect on the $T_{b} /$ rain-rate relationship. An equivalent measure of rain rate coincides with a lower $T_{b}$ when faster wind speeds are estimated by the ERA-Interim.

Figure 3 demonstrates that when quantifying rain rate as a function of $T_{b}$, the background CWV, SST, and wind speed need to be accounted for. In this analysis we do this by calculating the mean relationship between rain rate and $T_{b}$ within bins of each confounding variable. Bins are determined by a three-dimensional plot of collocated CloudSat and $T_{b}$ observations with the $x, y$, and $z$ axes representing the CWV, SST, and wind speed of each observation. A three-dimensional grid of bin boundaries is then established based on $1 \sigma$ standard deviation bins of each variable. For each variable along each axis there are six bins: $x>3 \sigma, 3 \sigma>x>2 \sigma, 2 \sigma>$ $x>1 \sigma, 1 \sigma>x>0 \sigma,-1 \sigma<x<0 \sigma,-2 \sigma<$ $x<-1 \sigma,-3 \sigma<x<-2 \sigma, x<-3 \sigma$. Two-dimensional projections of this plot are shown in Fig. 4 with grid lines indicating bin boundaries. This scheme allows for $6^{3}$ or 216 total bins; however, the majority of the bins are not well populated with observations, with only 77 containing enough observations to derive meaningful $T_{b} /$ rain-rate relationships, this is explained in further detail below. Bins with too few observations are assigned a missing value, though they may be populated when applying this routine to a larger area for a longer time. 

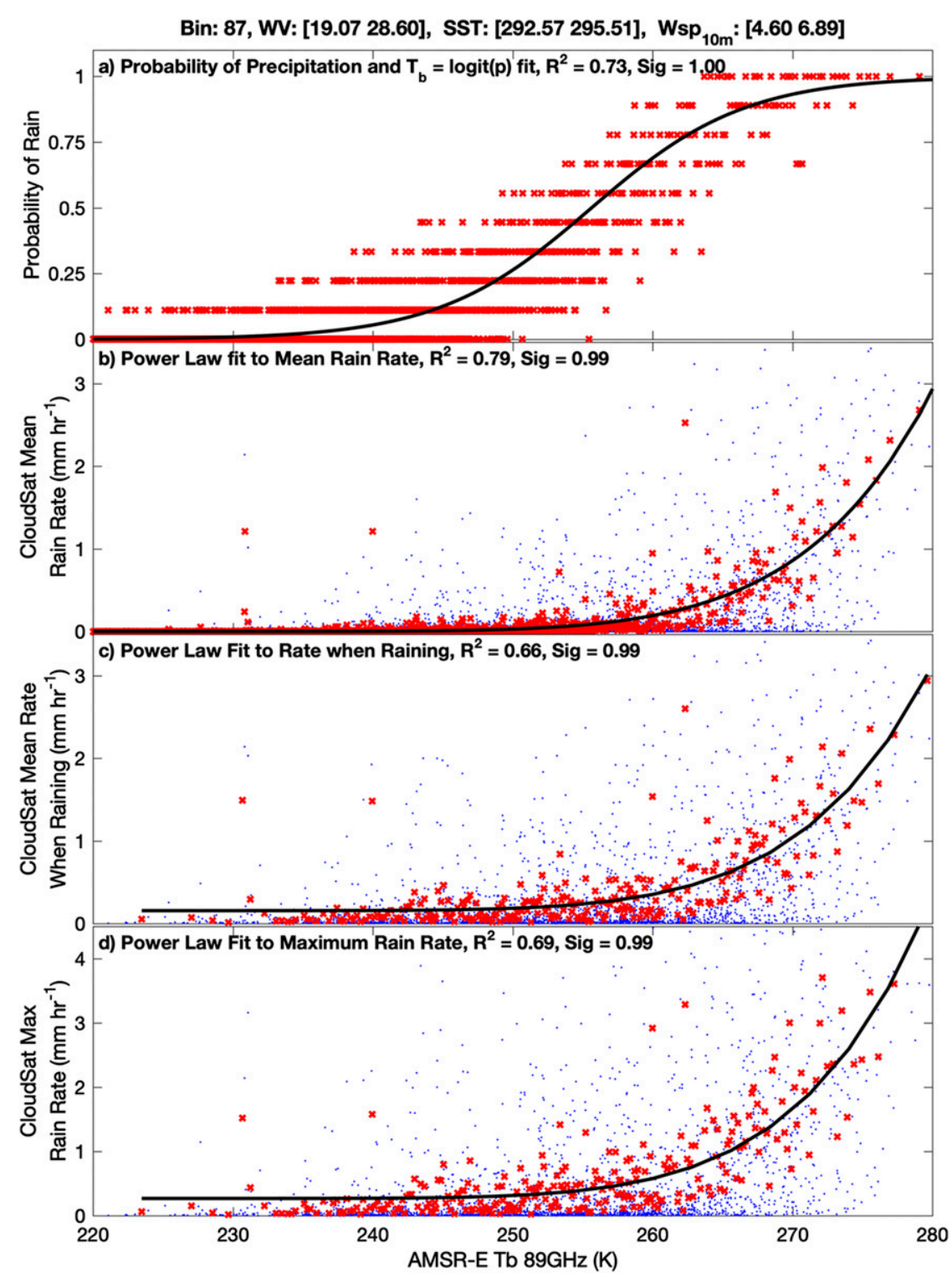

FIG. 6. (a)-(d) Fits to collocated CloudSat rain-profile rain-rate statistics and AMSR-E $T_{b}$ for a single CWV/SST/WSP bin. Blue dots represent collocated observations ( 1 in 20 shown). Red crosses represent bin means (along $x$, in $T_{b}$ space) of 9 collocated observations, which are used for curve fitting. The black line in (a) represents a linear fit to the $T_{b}=\operatorname{logit}(p)$ relationship. The black lines in (b), (c), and (d) represent power-law fits. The $R^{2}$ value indicates the percentage of variance explained by the fit, and Sig (significance) indicates the significance level of the variance explained by the fit. Bins are only included in this work if the significance level exceeds the $95 \%$ threshold.

As mentioned above, there are several CloudSat observations within each AMSR-E $T_{b}$ pixel. This is likely another source of noise seen in Fig. 2 since the multiple CloudSat observations within each $T_{b}$ pixel will not all be identical. Figure 5 shows an example of an AMSR-E pixel that is observed to be raining by CloudSat. Within the pixel there are five CloudSat samples, with four seeing rain. Using these five observations we can determine four statistics for the pixel describing the character of the rainfall: 1) the probability that the pixel contains rainfall, which is a binary result for each pixel: if any CloudSat observation within the pixel observes rain, the probability is set to 1 , otherwise 0 ; 2) the mean rain rate, which is the mean of all precipitating and nonprecipitating CloudSat rain rates within the pixel;3) the mean rate when raining, which is the mean rain rate for only the raining observations (this is also known as a conditional rain rate); 4) the 


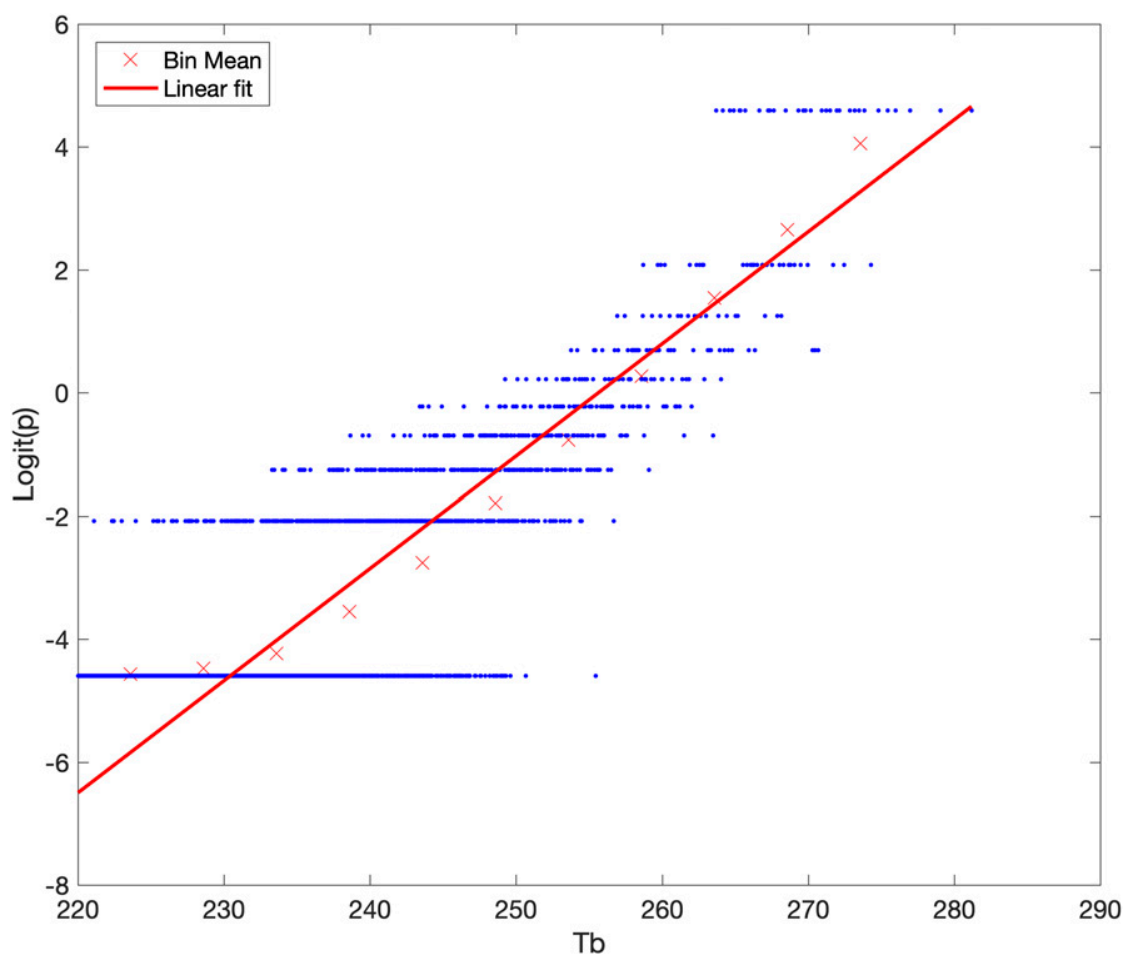

FIG. 7. Logit $(p)$ plotted as a function of $T_{b}$ from Fig. 6a; $p$ is the fraction of collocated CloudSat observations that detect any precipitation within an AMSR-E pixel. Blue dots represent red crosses from Fig. 6a. Here, red crosses represent $5-\mathrm{K}$ bin mean logit $(p)$ values. The red line is the linear fit to the red crosses. Uniform binning across the $x$ axis is vital because of the uneven distribution of points along $x$, which causes the linear fit to favor the cluster of points at low $T_{b}$ values, flattening the fit.

maximum rain rate observed by CloudSat. The latter three of these values are shown in Fig. 5, with the black line indicating the mean rain rate, the blue line indicating the mean rate when raining, and the red line showing the maximum rate.

The relationship between $T_{b}$ and precipitation is seen for a year of data within one CWV/SST/wind speed bin in Fig. 6. Individual collocated observations are shown as blue dots in Figs. 6b-d. Red crosses are the mean of nine consecutive (in $T_{b}$ space, along the $x$ axis of the plot, explanation below) individual, collocated observations. Curves are fit to these red crosses (detailed below) and represent the mean relationship between $T_{b}$ and rain rate within this box. The red crosses are used for curve fitting because they are much less noisy, so allow for more efficient and stable fitting routines.

A brief experiment was run to determine the optimum number of observations to be binned into the red crosses in Fig. 6. If too few observations are combined, then the plots are too noisy for fitting, but if too many observations are combined, then the plots have too few points to allow for reliable curve fitting. To optimize this, the number of individual observations averaged into bins (represented by crosses) was varied between 1 and 30 , then curves were fit to the crosses in each CWV/SST/wind speed bin. Coefficients defining the curves (described below) were only returned if the variance in rain rate explained by the fit (where rain rate is a function of $T_{b}$ ) was significant at or above the $95 \%$ level (meaning the correlation between rain rate predicted by the fit and the measured rain rate was significant at the $95 \%$ level). The greatest number of CWV/SST/wind speed bins with statistically significant fits was achieved when nine individual, collocated $T_{b}$ and rain-rate observations were combined, allowing for good fits in $77 \mathrm{CWV} / \mathrm{SST} /$ wind speed bins.

Figure 6a shows only red crosses and omits the individual, binary probability points. The figure shows greater probability of rain with increased $T_{b}$. The curve shown in black is calculated by fitting a straight line to the relationship $T_{b}=\operatorname{logit}(p)$, where $p$ is the probability of rain. The linear fit to the logit function is shown in Fig. 7. We chose the linear fit to the logit function for its superior behavior at the lower and upper $T_{b}$ limits where it asymptotes to $p=0$ and $p=1$, respectively. To improve the representativeness of the fit $T_{b}$ values are 


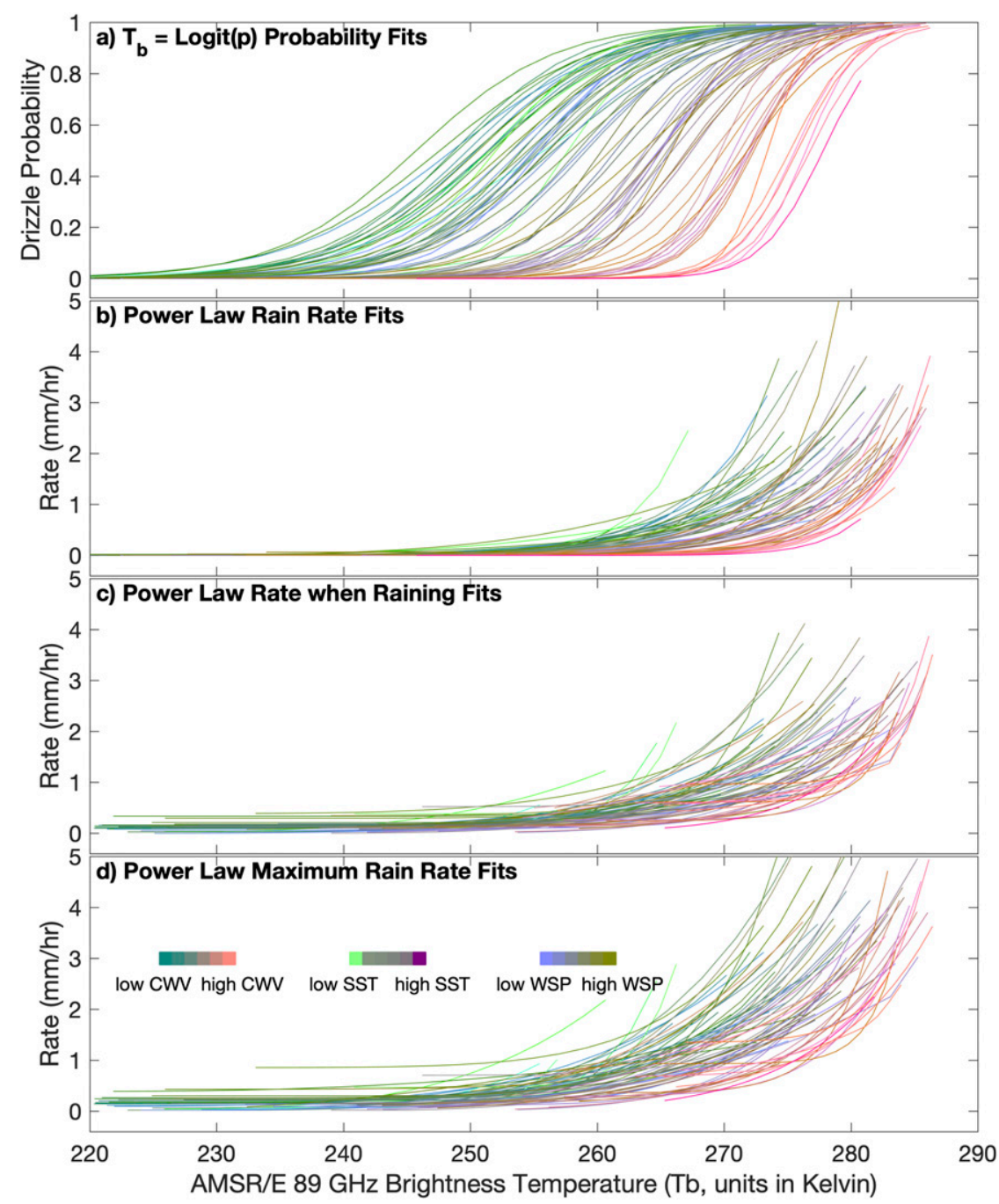

FIG. 8. Spaghetti plots showing all fits to (a) precipitation probability as a function of $T_{b}$, and (b) mean rain rate, (c) rain rate when raining, and (d) maximum rain rate as a function of $T_{b}$ for all 77 available bins. Line colors represent the CWV, SST, and WSP of each bin as shown by the color key in (d).

excluded at temperatures below the coolest drizzling temperature. This eliminates nonlinear behavior in the scatterplot where $T_{b}$ continues to decline, but drizzle is not present. The linear fit does not perfectly characterize the behavior of the data, but provides a simple fit that is reliably well behaved at high and low $T_{b}$ values. The logit function is defined below:

$$
\operatorname{logit}(p)=\log \left(\frac{p}{1-p}\right)
$$

Figure $6 \mathrm{~b}$ shows mean rain rate plotted as a function of $T_{b}$. In Fig. $6 \mathrm{~b}$ as well as Figs. $6 \mathrm{c}$ and $6 \mathrm{~d}$, the black curve represents a power-law fit to the data of the type

$$
\text { rate }=A \times T_{b}^{B}+C,
$$

where the coefficients $A, B$, and $C$ are determined using a robust power-law regression after scaling $T_{b}$ between 0 and 1 for $T_{b}$ range $220 \mathrm{~K}>T_{b}>290 \mathrm{~K}$. Figures $6 \mathrm{c}$ and $6 \mathrm{~d}$ use the same technique to fit the mean rate when raining and maximum rate when raining, respectively, as a function of $T_{b}$. Curves are fit to the red crosses (9-point mean value along $x$ ) not the individual observation points.

The routine outlined above is applied to all $77 \mathrm{CWV} /$ SST/wind speed bins that contain enough data to calculate these fits and show a $95 \%$ significance or above. Coefficients for each curve are calculated only for the range of $T_{b}$ values seen in our year of collocated data, so 


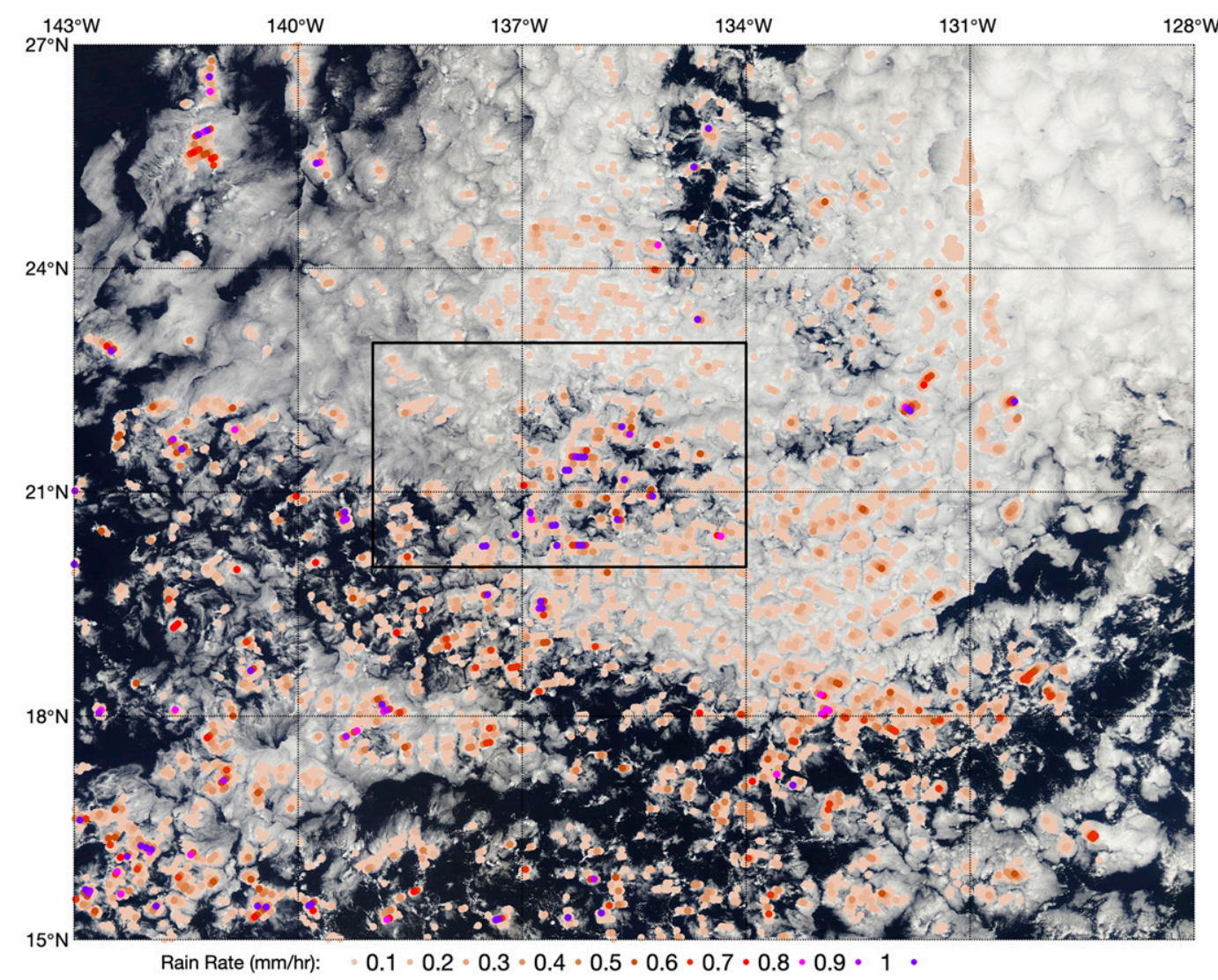

FIG. 9. A MODIS visible satellite image from 23 Jan 2007 in the northeast Pacific with estimated rain rates overlaid. Colored dots represent estimated average rain rates derived from $89-\mathrm{GHz} T_{b}$ for all probabilities of rainfall. The black rectangle shows the region plotted in Fig. 10. The difference in swath width between the AMSRE sensor and MODIS is apparent on the eastern edge of the figure, where MODIS cloud observations continue outside the observable domain of AMSR-E.

no extrapolation takes place. Each individual curve and its $T_{b}$ range is shown in the spaghetti plots in Fig. 8. To estimate rainfall statistics as a function of all $T_{b}$ within our subtropical study regions, we then apply the coefficients derived from the fits to the $T_{b}$ data across the entire AMSR-E swath for each CWV/SST/wind speed bin. Brightness temperatures that fall outside the range for each bin illustrated in Fig. 8 are flagged and assigned to the maximum or minimum $T_{b}$ at whichever end of the range was exceeded. Bin boundaries, linear fit coefficients, and power-law fit coefficients for mean rain rate, rate when raining, and maximum rain-rate estimates are available in the online supplemental material in supplemental Tables $1-5$, respectively. Tables also show the significance level of each fit and the number of individual CloudSat observations contributing to each fit is listed in supplemental Tables 3-5.

It is possible for the curve-fitting routines described above to estimate higher mean rates than mean rates when raining, and higher mean rates when raining than maximum rates. This is avoided by establishing minimum bounds on the fitting routine, so that the curve fit to rate when raining data cannot be lower (in $y$ ) than the mean rate and the curve fit to the maximum rate cannot be lower than the curve for the rate when raining.

Brightness temperature observations may be affected by the presence of ice clouds. To ensure that our precipitation estimates are not biased by this we filter for scenes where ice clouds are detected by MODIS. If the MODIS L2 cloud-top temperature observation nearest any $T_{b}$ pixel has a temperature below $263 \mathrm{~K}$, it may contain ice, so the $T_{b}$ pixel is excluded from the analysis.

\section{Results}

Figure 9 shows an example of AMSR-E 89-GHz rainrate estimates plotted along with the corresponding MODIS visible imagery in the northeast Pacific region. Mean rain rates are shown as orange and purple dots, with the color scale shown at the bottom of the figure. 


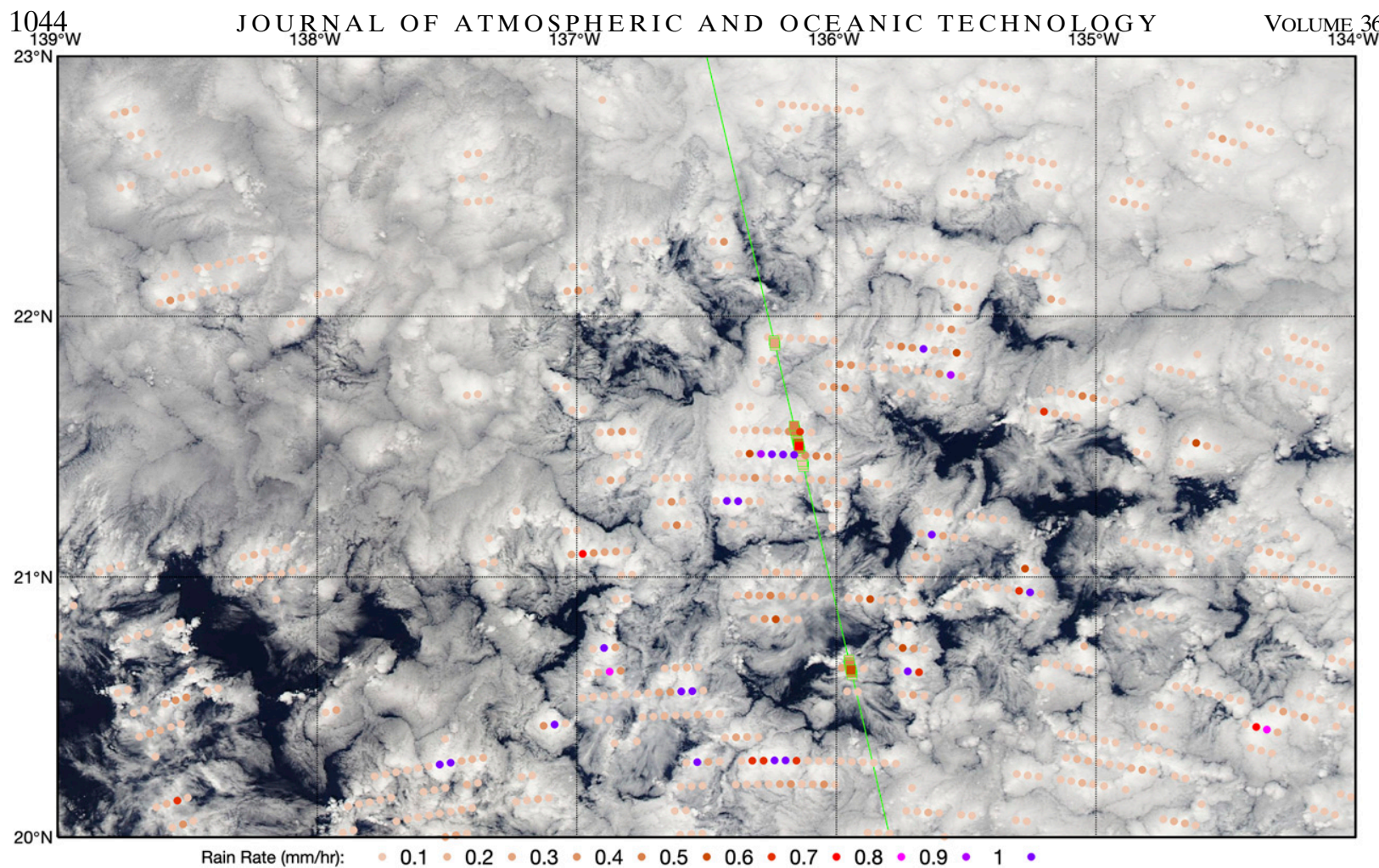

FIG. 10. A closer look at several open cells embedded in closed cells from the rectangle shown in Fig. 9. The same plotting conventions apply. The green line shows the track of CloudSat. Colored squares represent the CloudSat rain rates using the same color scheme as the $T_{b}$-derived values.

Rain rates estimated from AMSR-E $T_{b}$ correspond spatially very well with variations in cloud cover. Generally, rain is observed in the cores of both open and closed Sc cells. In this scene, open or more broken Sc cells tend to show smaller clusters of precipitation with higher rain rates than closed Sc cells, agreeing with the conclusions of Comstock et al. (2007).

In Fig. 10, a small portion of Fig. 9 (illustrated by the black box in Fig. 9) is shown in greater detail. The CloudSat curtain is shown as a green line and CloudSat precipitation observations are shown as squares, with a color scale matching the AMSR-E scale shown below the map. Here we show the precipitation pattern for open cells embedded within a region of closed cells. Spatial correspondence is again seen not only with the MODIS cloud-cover imagery, but with the collocated CloudSat retrievals. The heaviest rain rates are seen near the edges of the field of open cells, where closed cells may be transitioning to open. Agreement with CloudSat retrievals is seen in a lightly drizzling closed cell near the top of the figure and in two heavier drizzling open cells below.

Climatologies of our four precipitation products have been made by averaging rain rate and probability estimates from all available days in 2007 on a regular latitude-longitude grid for day and night separately.
Two are shown here. Figure 11 shows the mean probability of rainfall at night for our four study regions on a $2.5^{\circ} \times 2.5^{\circ}$ grid. We choose this relatively coarse grid to minimize noise and highlight large-scale features within the four regions. Drizzle is more frequent offshore where the planetary boundary layer tends to be deeper and $\mathrm{Sc}$ begins its transition to trade $\mathrm{Cu}$. Drizzle is least frequent near the continents where coastal clear areas or very shallow Sc decks are more common. Probabilities of drizzle are lower farther west in the downwind portions of our study regions where the boundary layer tends to be deep, but cloud cover is less expansive.

Maps of probabilities of night time drizzle in Fig. 11 compare well with the maps of drizzle frequency in Leon et al. (2008, their Fig. 4), Mülmenstädt et al. (2015, their Fig. 3b), and Rapp et al. (2013, their Fig. 3a), though just in the southeast Pacific. All of these works show precipitation frequency/probability maxima offshore and downwind in the Sc regions, and both our Fig. 11 and Leon et al. (2008, their Fig. 4) show that the southeast Pacific has the most frequent drizzle, while drizzle frequency is lower in the northeast Pacific, lower yet in the southeast Atlantic, and lowest in the eastern Indian Ocean. In comparing those works, the values for drizzle frequencies differ because of different thresholds and 

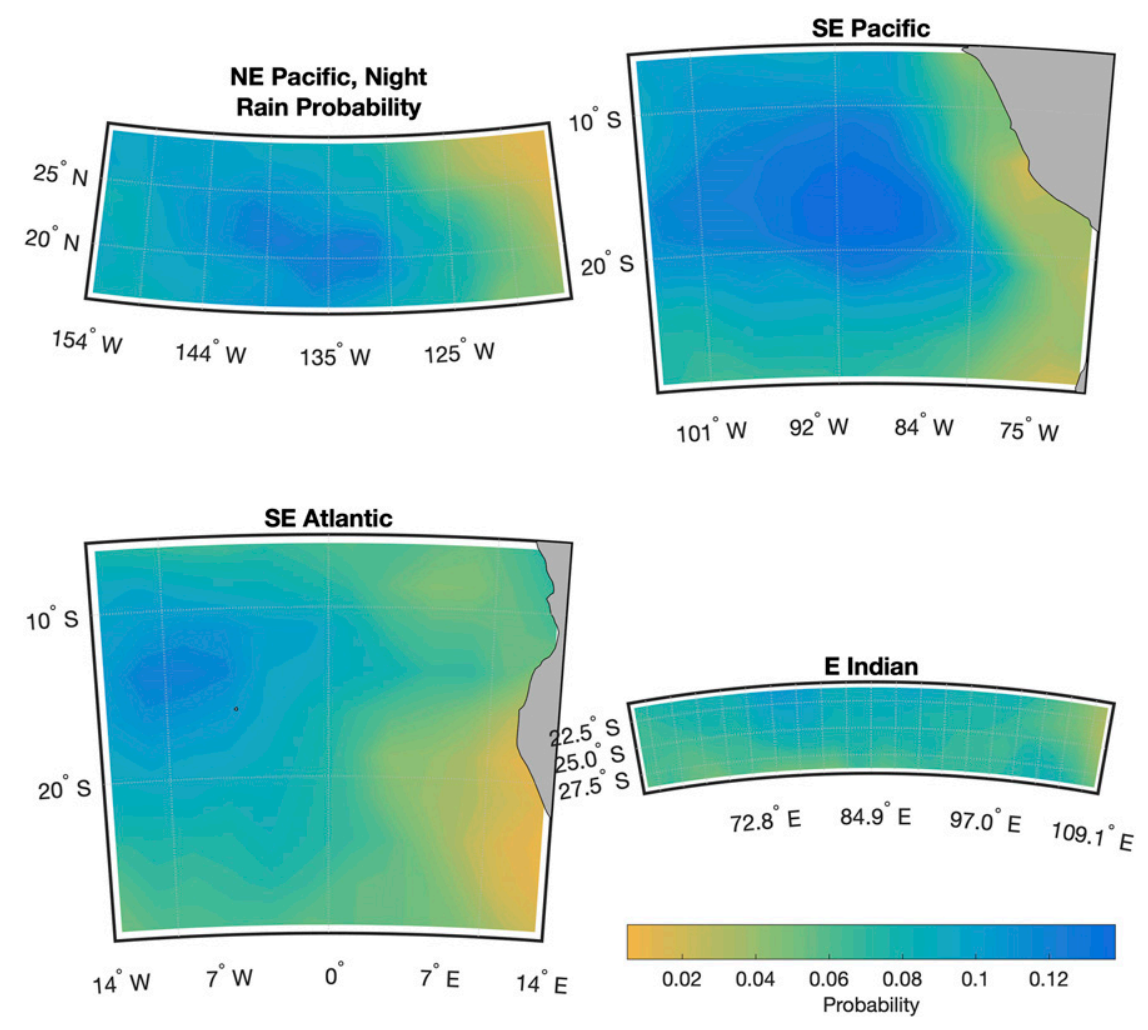

FIG. 11. Nighttime mean probabilities of rainfall averaged on a $2.5^{\circ} \times 2.5^{\circ}$ latitude-longitude grid for all of 2007. Blue colors indicate greater rainfall likelihoods.

metrics used, but the geographic distribution of drizzle features compare well.

In Fig. 12, we show the nighttime mean rain rates on a $2.5^{\circ} \times 2.5^{\circ}$ grid, again to show large-scale features and minimize noise. The spatial patterns of these rain rates do not directly correspond to the probabilities seen in the prior figure. Instead, rain rates are strongest farther offshore, where the sea surface is warmer and the boundary layer is deeper, suggesting that rain rates are influenced by sea surface temperature and boundary layer depth. The lowest rain rates occur nearer the coasts in regions where shallow boundary layers are common. A comparison of Fig. 12b with Rapp et al. (2013, their Fig. 5b) shows a similar location for the maximum mean rain rate in the southeast Pacific, at around $18^{\circ} \mathrm{S}, 100^{\circ} \mathrm{W}$, as well as a similar tendency toward lower rates near the South American continent.

As a check on rain estimates derived from the AMSRE 89-GHz $T_{b}$ retrievals, rates are compared back against the CloudSat Rain Profile retrievals used to drive the $T_{b}$ regression. In Fig. 13, AMSR-E 89-GHz mean rain-rate estimates are compared to collocated corresponding CloudSat observations within each pixel for January 2007. Mean CloudSat rain rate, variance, and the number of individual CloudSat observations are plotted for bins of $89-\mathrm{GHz}$ rain rate in Figs. 13a-c. Figure 13a shows the mean plus standard error bounds of collocated CloudSat rain rate as a function of AMSR-E rain-rate estimates. The relationship is very strong for rates less than $2 \mathrm{~mm} \mathrm{~h}^{-1}$, often falling exactly on the $1: 1$ line shown in blue. Variance increases with rain rate until around $2.5 \mathrm{~mm} \mathrm{~h}^{-1}$ when variance levels off with increasing rain rate. The initial increase in variance with rain rate is likely due to the spotty, irregular nature of heavier drizzle cells as seen in Figs. 9 and 10. In these heavier cells, small convective cores are typically surrounded by regions of light rain, allowing for the higher-resolution CloudSat to sample a wider range of rain rates within a single AMSR-E pixel. Standard error bounds increase with rain rate, likely because of declining sample sizes, shown on the logarithmic plot in Fig. 13c.

An additional comparison is made between our CloudSat-tuned AMSR-E $89-\mathrm{GHz}$ product and the currently available AE_Rain rain rates (Kummerow et al. 2015). Because the pixels are not matched in space, rain rates from both datasets were first averaged on a $0.2^{\circ} \times 0.2^{\circ}$ latitude-longitude grid for each day and night for all days in January of 2007. The resulting plot shows the mean AE_Rain rain rate as a function of the 

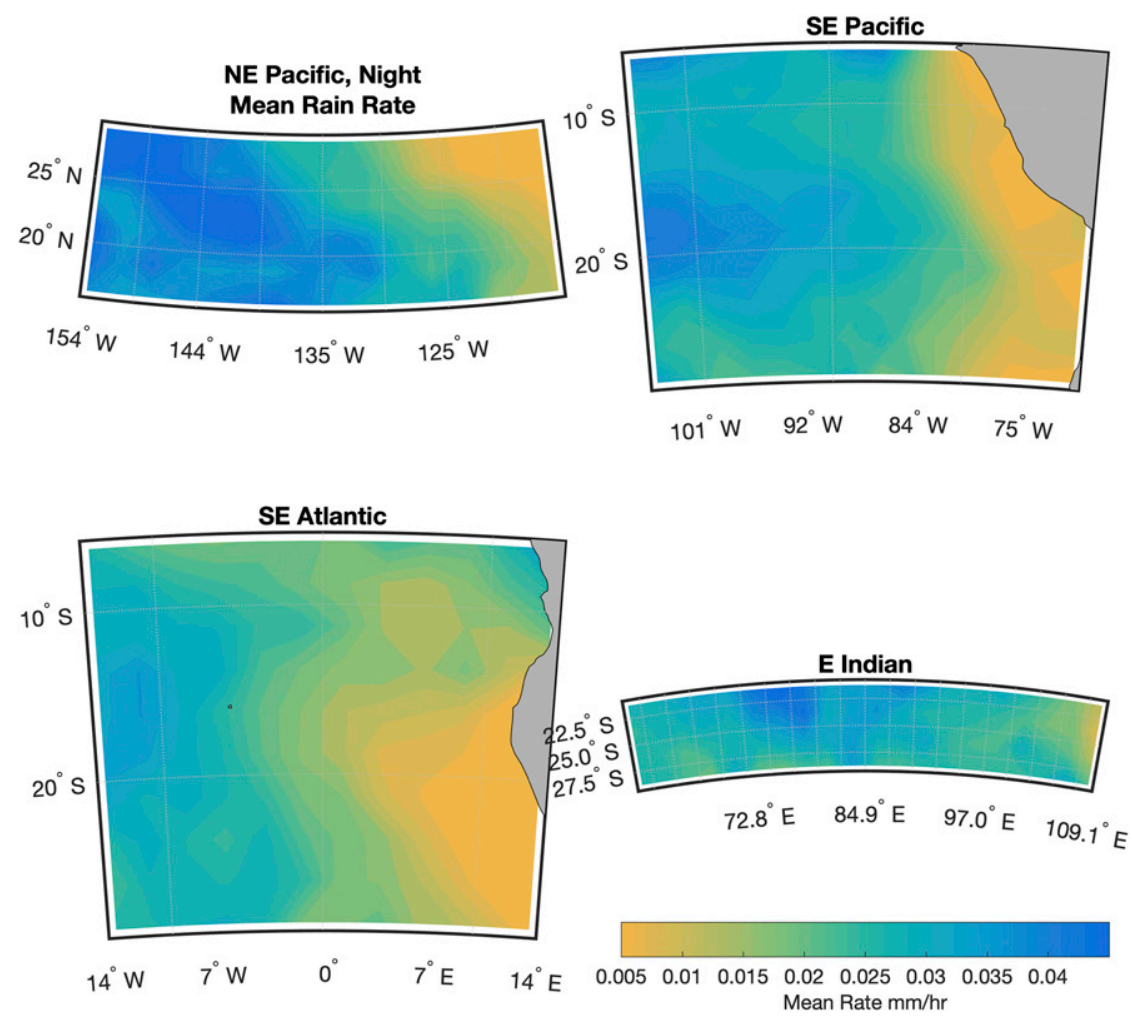

FIG. 12. Nighttime mean rain rates averaged on a $2.5^{\circ} \times 2.5^{\circ}$ latitude-longitude grid for all of 2007. Blue colors indicate heavier rainfall rates.

spatially and temporally collocated $89-\mathrm{GHz} T_{b}$ rain-rate estimates for all rain probabilities. Mean AE_Rain rain rates are shown as red dots with standard error bounds shown as thick, black lines. The slope of the $x-y$ plot in Fig. 14 is less steep than the 1:1 line. This means that the $89-\mathrm{GHz}$ estimates are sensing precipitation more frequently, or sensing greater rain rates compared to AE_Rain, thus indicating a greater sensitivity to light rain for the $89-\mathrm{GHz}$ product.

Conclusions drawn from Fig. 14 are supported by the maps shown in Fig. 15, where the spatial patterns of mean rain rates from both products are compared for one instance. Rates are compared for three thresholds of minimum precipitation probability: $10 \%, 25 \%$, and $50 \%$ (e.g., a $10 \%$ threshold includes only pixels with a greater than $10 \%$ probability of rain). The scene shown in Fig. 15 is for the same day and region as shown in Fig. 9, but with the northern boundary expanded to $30^{\circ} \mathrm{N}$ in order to sample a portion of a more organized synopticscale disturbance, and the eastern boundary contracted to $130^{\circ} \mathrm{W}$. Rain rates from both products are shown as colored dots using the same color scale as Figs. 9 and 10. The comparison shows that the AE_Rain product tends to overreport rain occurrence at low probabilities (Fig. 15d), so much so that nonzero rain rates are returned for most of the cloudy pixels seen in Fig. 9. As the threshold for minimum precipitation probability increases, the spatial distribution of AE_Rain rates begins to loosely match the distribution of rain rates shown by the $89-\mathrm{GHz} T_{b}$ product, but AE_Rain shows little variation in rate compared to the $89-\mathrm{GHz}$ product, with the AE_Rain rates uniformly low. In the upper left, a larger region of precipitation associated with a frontal boundary is well-sampled by both products for all three thresholds. These results show that the $89-\mathrm{GHz}$ product presented here offers improved sensitivity to light rain compared to the currently available AE_Rain product.

\section{Discussion}

This AMSR-E 89-GHz precipitation product provides an improvement in drizzle detection compared with existing products, with a greater sensitivity to light rain compared to the currently available AE_Rain passive microwave product. The $89-\mathrm{GHz} T_{b}$ rain-rate estimates also offer wider spatial sampling compared to CloudSat, though the $T_{b}$ product is lacking the vertical resolution and fine along-track resolution offered by CloudSat. Equally as important, the new product provides a unique, large-scale view of the spatial organization of 


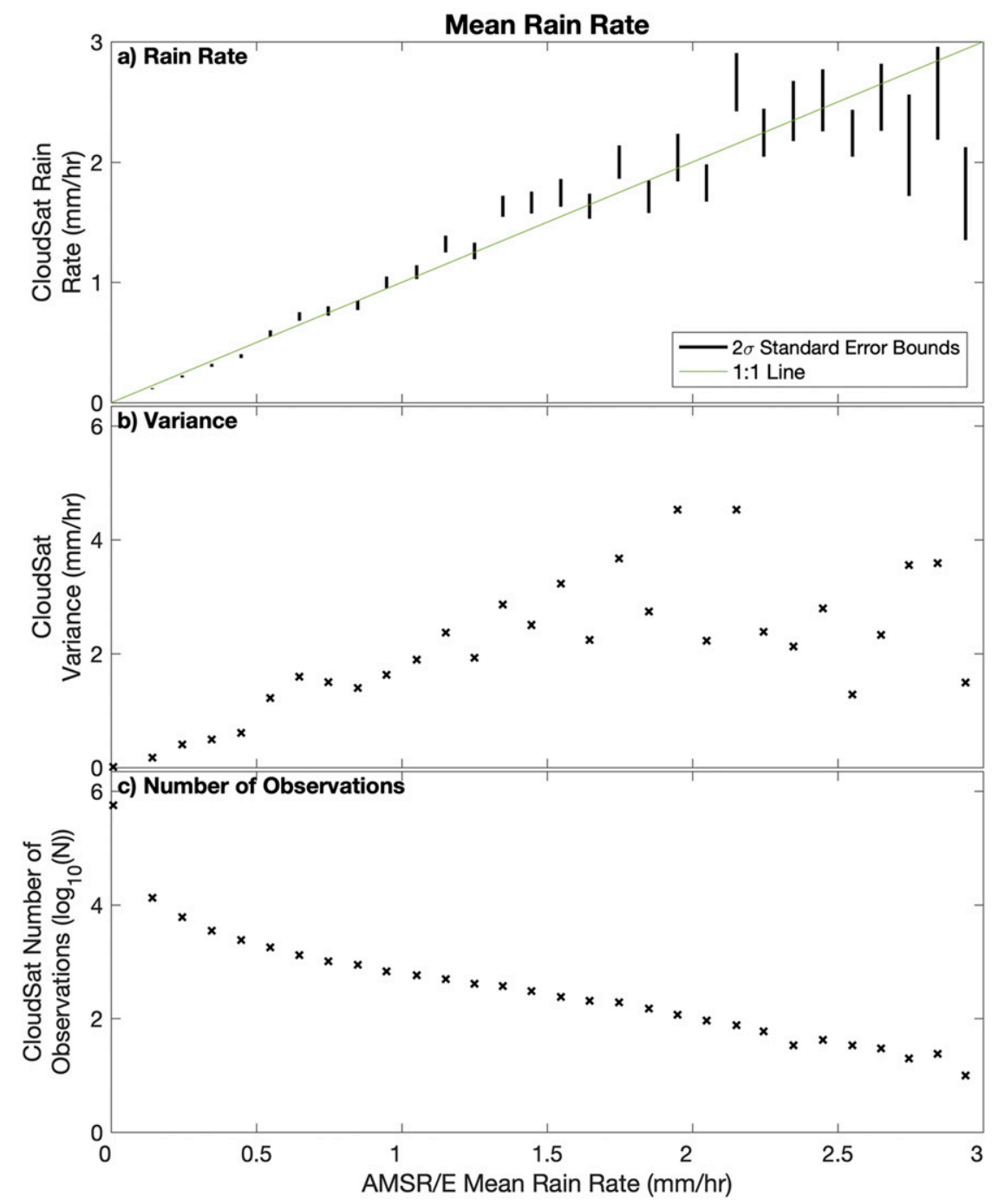

FIG. 13. CloudSat rain profile (a) mean rain rates, (b) variance of rain rate, and (c) number of collocated CloudSat observations as a function of AMSR-E 89-GHz $T_{b}$-derived rain rates for rain-rate bin widths of $0.1 \mathrm{~mm} \mathrm{~h}^{-1}$. A 1:1 line is shown as a green line in (a). Data are for January 2007.

drizzle within shallow marine clouds that has heretofore been elusive.

In Kalmus and Lebsock (2017), CloudSat rain-profile R04 was shown to be biased in warm rain environments because of inadequacies in the evaporation-sedimentation model used to estimate surface rain rates. This bias produced an overestimation of rain rates. An improved rainprofile dataset (R05) will soon be released, which compares more favorably with other collocated radar observations. When the R05 update is released, we will update these rain-rate estimates using the improved CloudSat R05 training data. Additionally, the coarse-binning routine currently employed by this routine may be refined in order to reduce discontinuities associated with bin boundaries.
This style of algorithm could be applied to retrievals from other microwave sensors aboard satellites or aircraft using other radar observations to tune $T_{b}$ observations using recomputed regressions, allowing for better rain detection over remote oceanic regions not observed by any radars. Any future applications would rely on other methods for screening for ice clouds and would require accommodating different sensor geometries. The limited geographic extent currently offered by these estimates is a significant drawback; however, expansion into the rest of the subtropics and convection-free regions of the tropics is planned. Ultimately, this algorithm could be used to evaluate precipitation datasets such as the Integrated 


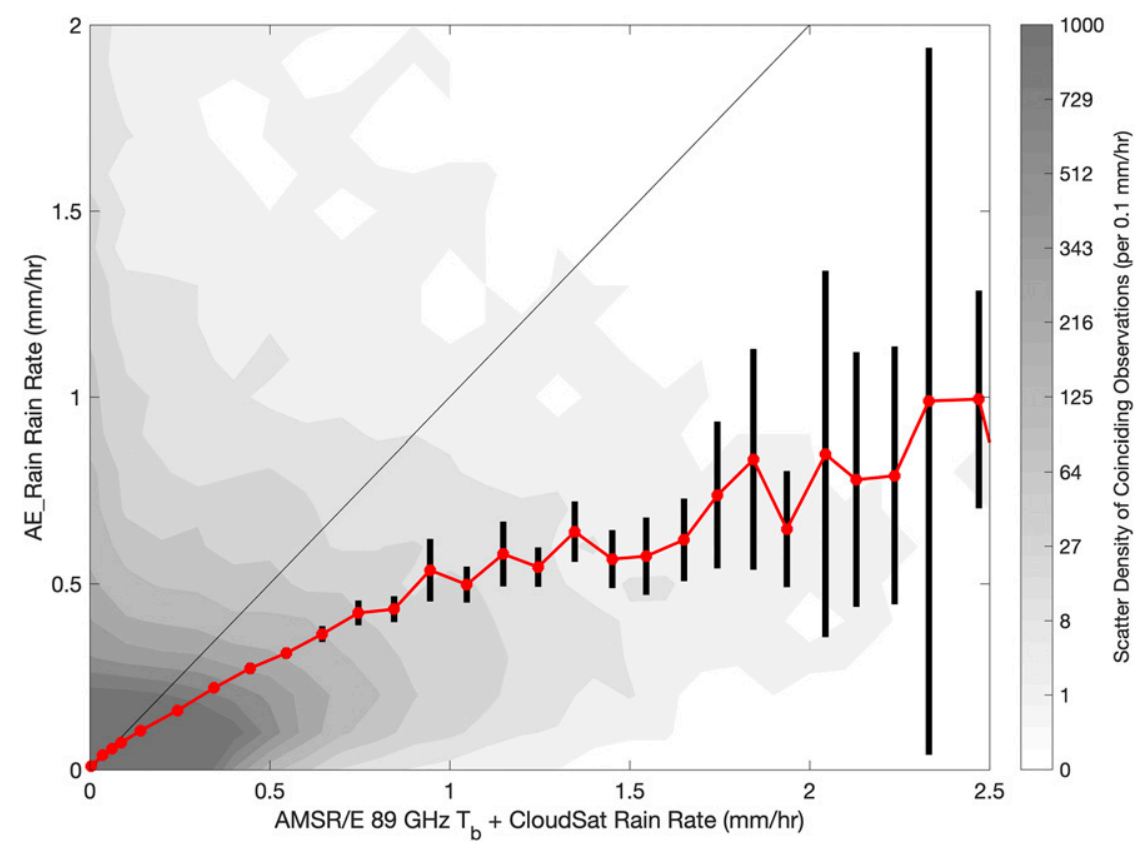

FIG. 14. Bin mean AE_Rain rain rates as a function of collocated CloudSat + AMSR-E 89-GHz $T_{b}$ rain rates with $2 \sigma$ standard error bounds shown as vertical bars. Mean rates are calculated for both products on a $0.2^{\circ} \times 0.2^{\circ}$ latitude-longitude grid, twice daily for all four Sc regions on all days of January 2007. A diagonal, black 1:1 line is shown. A scatter density plot is shown as the gray contour, indicating how many observations are matched per $0.1 \mathrm{~mm} \mathrm{~h}^{-1}$ box. Data are for January 2007.

Multisatellite Retrievals for GPM (IMERG) dataset (Huffman et al. 2018), or the optimal estimation precipitation retrieval method used in Duncan et al. (2018). Finally, the warm rain rates calculated here could be used to aid in tuning new neural networkbased algorithms (Sanò et al. 2018)

This new rainfall product will have several immediate applications. Rain rates associated with stratocumulus cellular structures and differing boundary layer depths can be compared in greater numbers. Precipitation processes during Lagrangian transitions in cloud cover can be assessed throughout the process. Additionally, climatologies for drizzle can be produced in greater temporal and spatial detail because of the widened spatial sampling compared with CloudSat. Applying this routine to $T_{b}$ observed by other orbiting microwave sensors could allow for even greater spatial and temporal coverage. Finally, this product can be used to further study complicated and difficult to observe precipitation-aerosol-cloud interactions.

\section{Conclusions}

We present an algorithm that estimates warm rain rates using $89-\mathrm{GHz}$ microwave brightness temperatures from the AMSR-E sensor on the Aqua satellite. The analysis is currently limited to four subtropical ocean basins. To produce estimates, first it is necessary to hold sea surface temperature, column water vapor, and wind speed constant in bins. This binning controls for the effects that those variables have on the relationship between $T_{b}$ and rain rate. Pixels that may contain ice clouds are removed. After controlling for these variables that modify the $T_{b} /$ rain-rate relationship, curves are fit to plots of CloudSat rain rate as a function of $T_{b}$. The coefficients that define these curves allow for estimates of precipitation statistics from $T_{b}$.

Each $4 \mathrm{~km} \times 6 \mathrm{~km} T_{b}$ pixel sampled by both AMSR-E and CloudSat usually contains 5 or 6 CloudSat rain-rate estimates. This allows for the calculation of several statistics within a pixel: the probability that rain is observed, the mean rain rate, the rate when raining, and the maximum rain rate. This algorithm produces these four estimates for each $T_{b}$ retrieval on an irregular $4 \mathrm{~km} \times 10 \mathrm{~km}$ grid currently for the year 2007. Although pixel sizes are $4 \mathrm{~km} \times 6 \mathrm{~km}$, the actual grid spacing is $4 \mathrm{~km} \times 10 \mathrm{~km}$ owing to gaps between pixels in the along-track direction.

Precipitation estimates using the AMSR-E 89-GHz $T_{b}$ are compared with MODIS visible imagery, CloudSat, and the AMSR-E AE_Rain rainfall product using lower-frequency microwave channels. Comparisons show that $89-\mathrm{GHz}$ precipitation estimates match well 

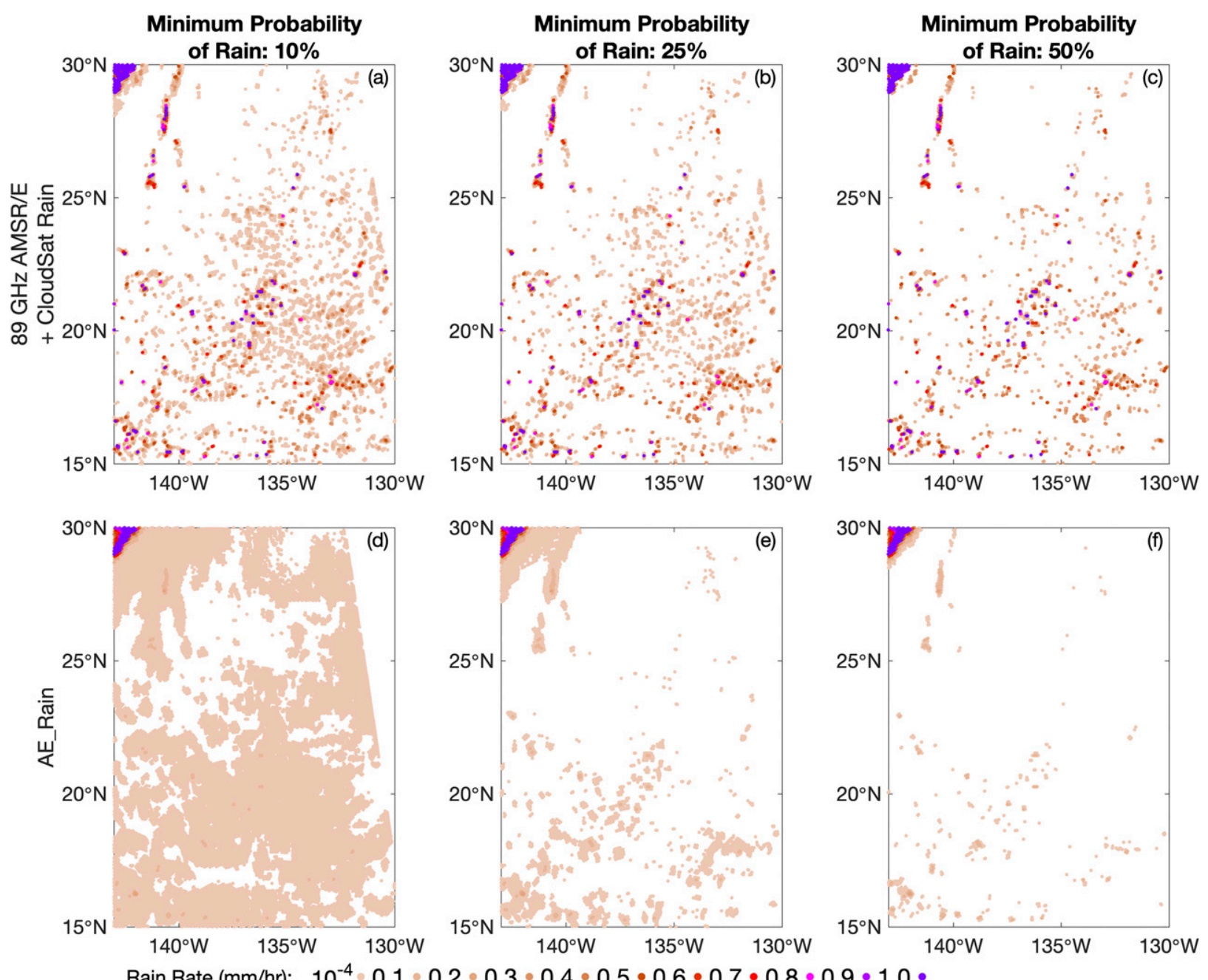

FIG. 15. Mean surface rain rates derived from (a)-(c) 89-GHz AMSR-E $T_{b}$ and CloudSat compared to rates from (d)-(f) AE_Rain for $23 \mathrm{Jan}$ in the northeast Pacific, observing the same scene as Fig. 9, but with an expanded northern boundary around 1330 LT 23 Jan 2007. Rain rates are plotted for three minimum precipitation probability thresholds: (left) $10 \%$, (center) $25 \%$, and (right) $50 \%$. Colors correspond to rain rates as shown in the legend along the base of the plot, with reds and purples indicating heavier drizzle.

with MODIS imagery, so that precipitation is observed in cores of open and closed cell stratocumulus. A comparison back against CloudSat rain rates shows excellent agreement at rain rates below $1 \mathrm{~mm} \mathrm{~h}^{-1}$ where comparison data are plentiful. Above that threshold, variances and errors tend to increase because of small size and spotty geographic distribution of heavy drizzle cells and limited sample sizes. A further comparison is made with the AE_Rain product, where the $89-\mathrm{GHz}$ product shows improved sensitivity to light rain. Mean climatologies of precipitation statistics appear reasonable, with maxima in precipitation probability near the $\mathrm{Sc}-\mathrm{Cu}$ transition regions and the strongest rain rates offshore and equatorward within our study regions, located where the SST is warmest and the boundary layer is deepest.
This product can be used to improve the study of several open questions in cloud and climate science requiring subdaily temporal resolution and wide geographic data availability. Climatologies of precipitation can be produced on a finer scale both temporally and spatially. Using this algorithm, the expansion of this product is anticipated in warm cloud regimes in order to make precipitation estimates available for all years with AMSR-E $T_{b}$ observations.

Acknowledgments. This work was supported by NASA Grant NNXBAQ35G. We thank Dr. Anita Rapp and two anonymous reviewers for their thorough attention to detail in reviewing and editing the manuscript. Part of the research described in this paper was carried out at the Jet Propulsion Laboratory, California Institute of 
Technology, under contract with the National Aeronautics and Space Administration.

\section{REFERENCES}

Abel, S. J., D. N. Walters, and G. Allen, 2010: Evaluation of stratocumulus cloud prediction in the Met Office forecast model during VOCALS-REx. Atmos. Chem. Phys., 10, 10 541-10 559, https://doi.org/10.5194/acp-10-10541-2010.

Ashcroft, P., and F. Wentz, 2006: AMSR-E/Aqua L2A global swath spatially-resampled brightness temperatures, version 2 . National Snow and Ice Data Center, accessed 30 October 2017, http://www.nsidc.org/data/amsre.

Bobak, J. P., and C. S. Ruf, 2000: Improvements and complications involved with adding an $85-\mathrm{GHz}$ channel to cloud liquid water radiometers. IEEE Trans. Geosci. Remote Sens., 38, 214-225, https://doi.org/10.1109/36.823914.

Burleyson, C. D., and S. E. Yuter, 2015a: Patterns of diurnal marine stratocumulus cloud fraction variability. J. Appl. Meteor. Climatol., 54, 847-866, https://doi.org/10.1175/JAMC-D-14-0178.1.

- and — 2015b: Subdiurnal stratocumulus cloud fraction variability and sensitivity to precipitation. J. Climate, 28, 29682985, https://doi.org/10.1175/JCLI-D-14-00648.1.

Comstock, K. K., R. Wood, S. E. Yuter, and C. S. Bretherton, 2004: Reflectivity and rain rate in and below drizzling stratocumulus. Quart. J. Roy. Meteor. Soc., 130, 2891-2918, https://doi.org/10.1256/qj.03.187.

, C. S. Bretherton, and S. E. Yuter, 2005: Mesoscale variability and drizzle in southeast Pacific stratocumulus. J. Atmos. Sci., 62, 3792-3807, https://doi.org/10.1175/JAS3567.1.

— S. E. Yuter, R. Wood, and C. S. Bretherton, 2007: The threedimensional structure and kinematics of drizzling stratocumulus. Mon. Wea. Rev., 135, 3767-3784, https://doi.org/ 10.1175/2007MWR1944.1.

Crewel, S., and U. Löhnert, 2003: Accuracy of cloud liquid water path from ground-based microwave radiometry 2 . Sensor accuracy and synergy. Radio Sci., 38, 8042, https://doi.org/ 10.1029/2002RS002634.

Dee, D. P., and Coauthors, 2011: The ERA-Interim reanalysis: Configuration and performance of the data assimilation system. Quart. J. Roy. Meteor. Soc., 137, 553-597, https://doi.org/ 10.1002/qj.828.

Duncan, D. I., C. D. Kummerow, B. Dolan, and V. Petković, 2018: Towards variational retrieval of warm rain from passive microwave observations. Atmos. Meas. Tech., 11, 4389-4411, https://doi.org/10.5194/amt-11-4389-2018.

Eastman, R., and R. Wood, 2016: Factors controlling low-cloud evolution over the eastern subtropical oceans: A Lagrangian perspective using the A-Train satellites. J. Atmos. Sci., 73, 331-351, https://doi.org/10.1175/JAS-D-15-0193.1.

Geoffroy, O., J.-L. Brenguier, and I. Sandu, 2008: Relationship between drizzle rate, liquid water path and droplet concentration at the scale of a stratocumulus cloud system. Atmos. Chem. Phys., 8, 4641-4654, https://doi.org/10.5194/ acp-8-4641-2008.

Hartmann, D. L., M. E. Ockert-Bell, and M. L. Michelsen, 1992: The effect of cloud type on Earth's energy balance: Global analysis. J. Climate, 5, 1281-1304, https://doi.org/10.1175/ 1520-0442(1992)005<1281:TEOCTO > 2.0.CO;2.

Huffman, G. J., and Coauthors, 2018: NASA Global Precipitation Measurement Integrated Multi-Satellite Retrievals for GPM (IMERG). NASA Algorithm Theoretical Basis Doc., version
5.2, 35 pp., https://pmm.nasa.gov/sites/default/files/document_ files/IMERG_ATBD_V5.2.pdf.

Jones, A. S., and T. H. Vonder Haar, 1997: Retrieval of microwave surface emittance over land using coincident microwave and infrared satellite measurements. J. Geophys. Res., 102, 13609 13 626, https://doi.org/10.1029/97JD00797.

Kalmus, P., and M. Lebsock, 2017: Correcting biased evaporation in CloudSat warm rain. IEEE Trans. Geosci. Remote Sens., 55, 6207-6217, https://doi.org/10.1109/TGRS.2017.2722469.

Kummerow, C., R. Ferraro, and D. Randel, 2015: AMSR-E/Aqua L2B global swath surface precipitation GSFC profiling algorithm, version 3. NASA National Snow and Ice Data Center Distributed Active Archive Center, accessed 1 November 2018, https://doi.org/10.5067/AMSR-E/AE_RAIN.003.

Lebsock, M. D., and T. S. L'Ecuyer, 2011: The retrieval of warm rain from CloudSat. J. Geophys. Res., 116, D20209, https:// doi.org/10.1029/2011JD016076.

_ G. L. Stephens, and C. Kummerow, 2008: Multisensor satellite observations of aerosol effects on warm clouds. J. Geophys. Res., 113, D15205, https://doi.org/10.1029/2008JD009876.

L'Ecuyer, T. S., and G. L. Stephens, 2002: An estimation-based precipitation retrieval algorithm for attenuating radars. J. Appl. Meteor., 41, 272-285, https://doi.org/10.1175/15200450(2002)041<0272:AEBPRA>2.0.CO;2.

Leon, D. C., Z. Wang, and D. Liu, 2008: Climatology of drizzle in marine boundary layer clouds based on 1 year of data from CloudSat and Cloud-Aerosol Lidar and Infrared Pathfinder Satellite Observations (CALIPSO). J. Geophys. Res., 113, D00A14, https://doi.org/10.1029/2008JD009835.

Mauger, G., and J. R. Norris, 2010: Assessing the impact of meteorological history on subtropical cloud fraction. J. Climate, 23, 2926-2940, https://doi.org/10.1175/2010JCLI3272.1.

Miller, M. A., and S. E. Yuter, 2013: Detection and characterization of heavy drizzle cells within subtropical marine stratocumulus using AMSR-E $89-\mathrm{GHz}$ passive microwave measurements. Atmos. Meas. Tech., 6, 1-13, https://doi.org/ 10.5194/amt-6-1-2013.

Mülmenstädt, J., O. Sourdeval, J. Delanoë, and J. Quaas, 2015: Frequency of occurrence of rain from liquid-, mixed-, and ice-phase clouds derived from A-Train satellite retrievals. Geophys. Res. Lett., 42, 6502-6509, https://doi.org/10.1002/ 2015GL064604.

Petty, G. W., 1994: Physical retrievals of over-ocean rain rate from multichannel microwave imagery. Part I: Theoretical characteristics of normalized polarization and scattering indices. Meteor. Atmos. Phys., 54, 79-99, https://doi.org/ 10.1007/BF01030053.

Platnick, S., and Coauthors, 2017a: The MODIS cloud optical and microphysical products: Collection 6 updates and examples from Terra and Aqua. IEEE Trans. Geosci. Remote Sens., 55 , 502-525, https://doi.org/10.1109/TGRS.2016.2610522.

_ , and Coauthors, 2017b. MODIS atmosphere L2 joint atmosphere product. Goddard Space Flight Center, accessed 4 June 2018, https://doi.org/10.5067/MODIS/MODATML2.06.

Randall, D. A., J. A. Coakley, C. W. Fairall, R. A. Knopfli, and D. H. Lenschow, 1984: Outlook for research on marine subtropical stratocumulus clouds. Bull. Amer. Meteor. Soc., 65 , 1290-1301, https://doi.org/10.1175/1520-0477(1984)065<1290 OFROSM $>2.0 . \mathrm{CO} ; 2$.

Rapp, A. D., M. Lebsock, and T. L'Ecuyer, 2013: Low cloud precipitation climatology in the southeastern Pacific marine stratocumulus region using CloudSat. Environ. Res. Lett., 8 , 014027, https://doi.org/10.1088/1748-9326/8/1/014027. 
Sandu, I., and B. Stevens, 2011: On the factors modulating the stratocumulus to cumulus transitions. J. Atmos. Sci., 68, 18651881, https://doi.org/10.1175/2011JAS3614.1.

Sanò, P., G. Panegrossi, D. Casella, A. C. Marra, L. P. D'Adderio, J.-F. Rysman, and S. Dietrich, 2018: The Passive Microwave Neural Network Precipitation Retrieval (PNPR) algorithm for the conical scanning GMI radiometer. Remote Sens., 10, 1122, https://doi.org/10.3390/ rs10071122.

Slingo, A., 1990: Sensitivity of the Earth's radiation budget to changes in low clouds. Nature, 343, 49-51, https://doi.org/ 10.1038/343049a0.

Stephens, G. L., and Coauthors, 2002: The CloudSat mission and the A-Train. Bull. Amer. Meteor. Soc., 83, 1771-1790, https:// doi.org/10.1175/BAMS-83-12-1771.

Stevens, B., W. R. Cotton, G. Feingold, and C.-H. Moeng, 1998: Large-eddy simulations of strongly precipitating, shallow, stratocumulus-topped boundary layers. J. Atmos. Sci., 55, 3616-3638, https://doi.org/10.1175/1520-0469(1998)055<3616: LESOSP $>2.0 . \mathrm{CO} ; 2$.

— , G. Vali, K. Comstock, R. Wood, M. C. van Zanten, P. H. Austin, C. S. Bretherton, and D. H. Lenschow, 2005: Pockets of open cells (POCs) and drizzle in marine stratocumulus.
Bull. Amer. Meteor. Soc., 86, 51-57, https://doi.org/10.1175/ BAMS-86-1-51.

Wentz, F. J., and T. Meissner, 2004: AMSR-E/Aqua L2B global swath ocean products derived from Wentz algorithm, version 2. National Snow and Ice Data Center, accessed 30 October 2017, https://doi.org/10.5067/AMSR-E/AE_OCEAN.002.

_ - _ C, C. Gentemann, and M. Brewer, 2014: Remote Sensing Systems Aqua AMSR-E (daily) environmental suite on $0.25^{\circ}$ grid. Remote Sensing Systems, accessed 21 March 2018, www.remss.com/missions/amsr.

Wood, R., K. K. Comstock, C. S. Bretherton, C. Cornish, J. Tomlinson, D. R. Collins, and C. Fairall, 2008: Open cellular structure in marine stratocumulus sheets. J. Geophys. Res., 113, D12207, https://doi.org/10.1029/2007JD009371.

C. S. Bretherton, D. Leon, A. D. Clarke, P. Zuidema, G. Allen, and H. Coe, 2011a: An aircraft case study of the spatial transition from closed to open mesoscale cellular convection over the southeast Pacific. Atmos. Chem. Phys., 11, 2341-2370, https://doi.org/10.5194/acp-11-2341-2011.

, and Coauthors, 2011b: The VAMOS Ocean-CloudAtmosphere-Land Study Regional Experiment (VOCALSREx): Goals, platforms, and field operations. Atmos. Chem. Phys., 11, 627-654, https://doi.org/10.5194/acp-11-627-2011. 